University of Louisville

ThinkIR: The University of Louisville's Institutional Repository

Electronic Theses and Dissertations

$12-2018$

\title{
Epidermal growth factor-like ligands regulate dimer selection.
}

Jamie S. Rush

University of Louisville

Follow this and additional works at: https://ir.library.louisville.edu/etd

Part of the Cell Biology Commons, Pharmacology Commons, and the Systems Biology Commons

\section{Recommended Citation}

Rush, Jamie S., "Epidermal growth factor-like ligands regulate dimer selection." (2018). Electronic Theses and Dissertations. Paper 3122.

https://doi.org/10.18297/etd/3122

This Master's Thesis is brought to you for free and open access by ThinkIR: The University of Louisville's Institutional Repository. It has been accepted for inclusion in Electronic Theses and Dissertations by an authorized administrator of ThinkIR: The University of Louisville's Institutional Repository. This title appears here courtesy of the author, who has retained all other copyrights. For more information, please contact thinkir@louisville.edu. 


\title{
EPIDERMAL GROWTH FACTOR-LIKE LIGANDS REGULATE DIMER SELECTION
}

\author{
By \\ Jamie S. Rush \\ A.S., Tulsa Community College, 1998 \\ B.S., University of Oklahoma, 2001
}

\author{
A Thesis Submitted \\ To The Faculty of the School \\ of Medicine of the University of Louisville \\ In Partial Fulfillment of the Requirements \\ For the Degree of \\ Master of Science in Pharmacology and Toxicology \\ Department of Pharmacology and Toxicology \\ University of Louisville \\ Louisville Kentucky
}

December 2018 
Copyright 2018 by Jamie S. Rush

All Rights Reserved 



\title{
EPIDERMAL GROWTH FACTOR-LIKE LIGANDS REGULATE DIMER SELECTION
}

\author{
By \\ Jamie S. Rush \\ Thesis approved on
}

November $8^{\text {th }}, 2018$

by the following Thesis Committee

Brian P. Ceresa, Ph.D.

Joshua L. Hood, M.D., Ph.D.

Paula J. Bates, Ph.D. 


\section{ACKNOWLEDGEMENTS}

Throughout the years, many people have had an impact on me, both in education and life. I first would like to thank my mentor, Dr. Brian P. Ceresa, for guiding me through life as a scientist, and helping me to be the best independent researcher I can be. I especially am grateful that he reminds me that there is no failure, just lessons learned. As scientist, we learn often. I would like to thank my committee members, Dr. Bates and Dr. Hood, for their guidance and perspective on my research.

Every researcher that has passed through the doors of the Ceresa lab was influential in my past, and influences my present and my future. I am grateful for the lessons learned and the friendships made along the way. However, I am most thankful for my first lab friend and collaborator, Dr. Peterson. We grew as scientist together, and I owe much of my success to her support, guidance and ability to help me laugh through the tough spots. Thanks to everyone in my lab network, without all of your help, shared supplies and shared knowledge I could not make science happen.

Finally, without the support of my family, I would have never started, let alone finished anything. My father is, and will always be my favorite chemistry teacher, thanks Mr. Hall. Thanks to my late mother for her dedication to my success, you were always there for my three sisters and myself, and we are all better people because of you. Lastly, thanks to my husband, Brandon, for loving me, laughing with me and laughing at me when you absolutely should. The winding road of life is more interesting and fun doing it side-by-side with you. 


\section{ABSTRACT \\ EPIDERMAL GROWTH FACTOR-LIKE LIGANDS REGULATE DIMER SELECTION \\ Jamie S. Rush}

November 8, 2018

There are thirteen known endogenous EGF-like ligands. We previously reported that Betacellulin (BTC) increases ligand-mediated corneal wound healing more than Epidermal Growth Factor (EGF) [Peterson et al. (2014) IOVS 55(5):287080], although the molecular reason for this is unknown. Despite being better at promoting wound healing via enhanced cell migration, BTC has reduced receptor affinity and weaker induction of EGFR phosphorylation. These data indicate that BTC's response is not due to enhanced affinity or EGFR-kinase activity. Receptor phosphorylation and proximity ligation assays indicate that BTC treatment significantly increases ErbB3 phosphorylation and EGFR:ErbB3 heterodimers. BTC traffics EGFR at a faster rate than EGF, without noticeable differences in effector signaling. Thus, we demonstrate that despite both ligands binding to the EGFR, BTC biases the EGFR to dimerize with ErbB3 and regulates the biological response through trafficking and unknown effectors. 


\section{TABLE OF CONTENTS}

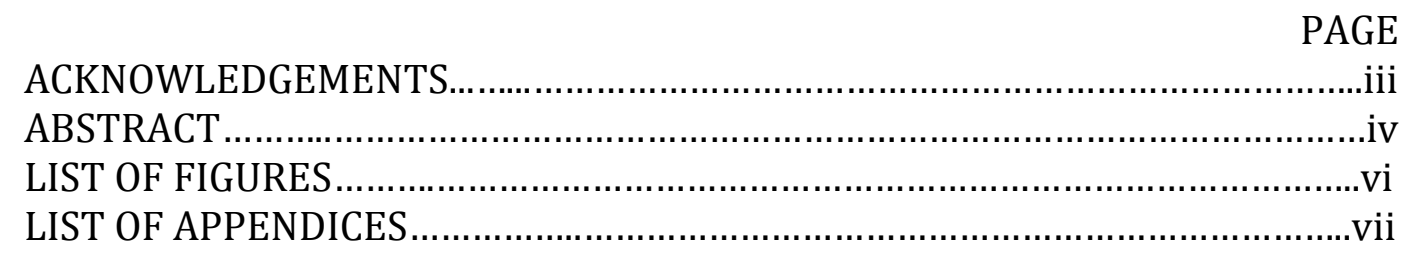

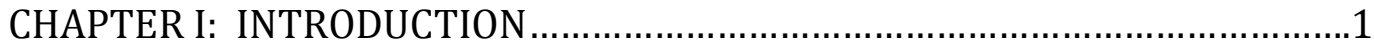

CHAPTER II: BETACELLULIN BIASES THE EGFR TO DIMERIZE WITH

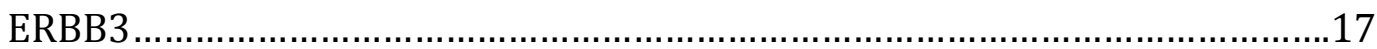

Introduction............................................................................... 17

Experimental Procedures.........................................................20

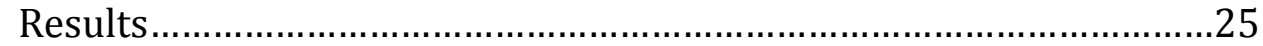

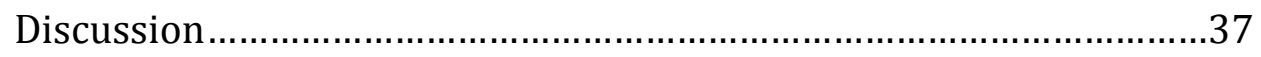

CHAPTER III: BETACELLULIN DIFFERENTIALLY EFFECTS TRAFFICKING AND COMPARABLY ACTIVATES AKT AND MAPK..........................................41

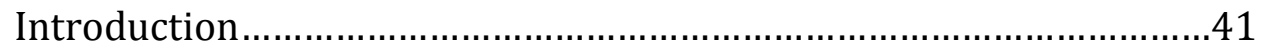

Experimental Procedures........................................................... 42

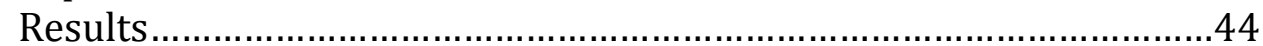

Discussion ............................................................................ 48

CHAPTER IV:SUMMARY AND CONCLUSIONS............................................... 51

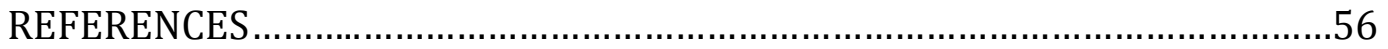

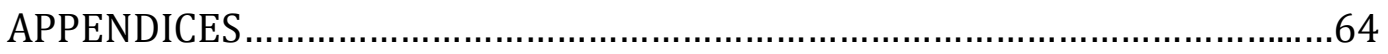

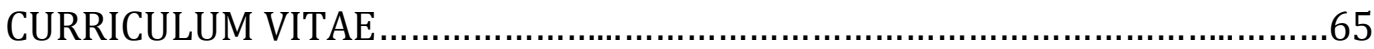




\section{LIST OF FIGURES}

FIGURE

PAGE

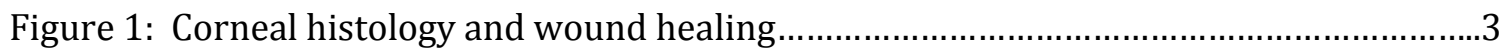

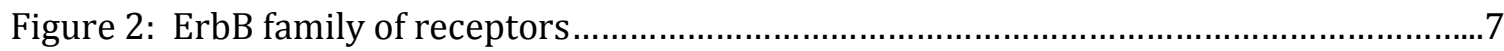

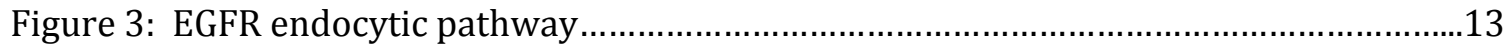

Figure 4: BTC is a more efficacious activator of cell migration than EGF............................26

Figure 5: BTC and EGF bind EGFRs with different affinities and $\mathrm{pH}$ sensitivities..................28

Figure 6: BTC is a less efficacious activator of EGFR phosphorylation in hTCEpi cells.........29

Figure 7: BTC is a less efficacious activator of EGFR phosphorylation in MDA-MB-468.......30

Figure 8: BTC induces ErbB3 phosphorylation in hTCEpi cells without ErbB2 ....................32

Figure 9: BTC induces ErbB3 phosphorylation in MDA-MB-468......................................33

Figure 10: BTC induces EGFR:ErbB3 heterodimers in hTCEpi cells....................................35

Figure 11: ErbB3 antagonist MM-121 and knockdown inhibit BTC-mediated migration to a

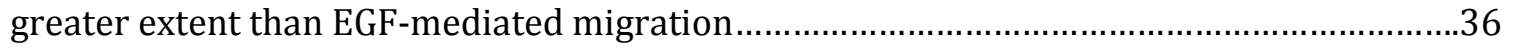

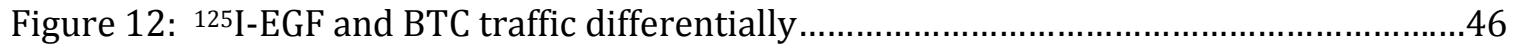

Figure 13: EGF and BTC have comparable effector signaling .............................................48 


\section{LIST OF APPENDICES}

PAGE

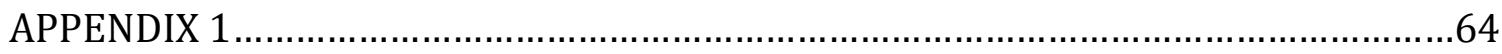




\section{CHAPTER I}

\section{INTRODUCTION AND LITERATURE REVIEW}

Epidermal growth factor receptor physiology

Epidermal growth factor receptor EGFR is the first receptor discovered of the four member ErbB family of receptors [1]. All ErbB receptors are receptor tyrosine kinases that share similarities including transmembrane orientation, structure, function and mechanism of action. ErbB receptors can form homo- and heterodimers with all family members and ligand-activated dimers initiate various intracellular signaling cascades. Each receptor and ligand combination differentially affects cell physiology, including our model, corneal epithelial homeostasis.

\section{Tissue Development}

EGFR has physiological roles that affect mammalian developmental biology as well as tissue maintenance and regeneration [2]. The critical role EGFR plays in developmental biology is most evident in EGFR null mice, which have non-viable embryos or underdeveloped pups that die shortly after birth [3]. The surviving pups display EGFR knockout specific defects in skin, hair, lungs and brain [4,5]. Defects of the skin associated with EGFR inhibition include dermatitis, decreased hair follicles, randomized direction of follicles, curly hair and shortened-curly vibrissae [6]. Lung 
changes with EGFR knockout mice include type II pneumocyte immaturity and thickened septae which can lead to pulmonary toxicity and interstitial lung disease [6]. Defective brain tissue attributed to loss of EGFR is complex but defined by three critical mechanisms of tissue development; 1) decreased proliferation 2) fewer new neurons reaching the olfactory bulb and 3) decreased neural cell migration.

Although defective regulation, mutations, and deletions of EGFR reveal the critical functions of the receptor, there are developmental cues that the role of EGFR changes during maturation. Fetal tissue ubiquitously expresses EGFR, but decreased number and density of EGFRs occurs in the subventricular zone in the brain during animal maturation, consistent with a critical role of EGFR in tissue development shifting to a less significant role in maintenance and regeneration $[7,8]$.

\section{Tissue Maintenance and Regeneration}

The corneal epithelium is one tissue in which the EGFR plays a critical role in tissue development and regeneration. Maintaining the structure and preserving the integrity of the cornea is critical to sustaining quality vision. The clear, convexshaped cornea has two main functions, to focus light into the eye, and to protect the eye from foreign agents. Anything that compromises the health and integrity of the cornea will affect the function. Blindness associated with corneal damage is a major ophthalmic public health problem. Corneal opacity afflicts 1.9 million people worldwide according to the World Health Organization [9]. Compromised corneal epithelium increases the risk of permanent corneal damage, as $28 \%$ of corneal

opacity blindness is associated with corneal damage [9]. The most common causes of 
corneal damage are accidental injury, surgery, ulcerations or abrasions caused by chronic disease or side effects from EGFR inhibitor drug therapy [10]. The cornea is comprised of three cell layers: the epithelium, stroma and the endothelium (Fig 1). Two additional layers, the Bowman's layer and the Descemet's membrane separate the individual cell layers. Fibroblast growth factor, keratinocyte growth factor, interleukins, hepatocyte growth factor and endothelin all promote healing in injured corneas [11-13]. However, only epidermal growth factor receptor (EGFR) signaling has been shown to be both necessary and sufficient for corneal wound healing (Fig 1B).

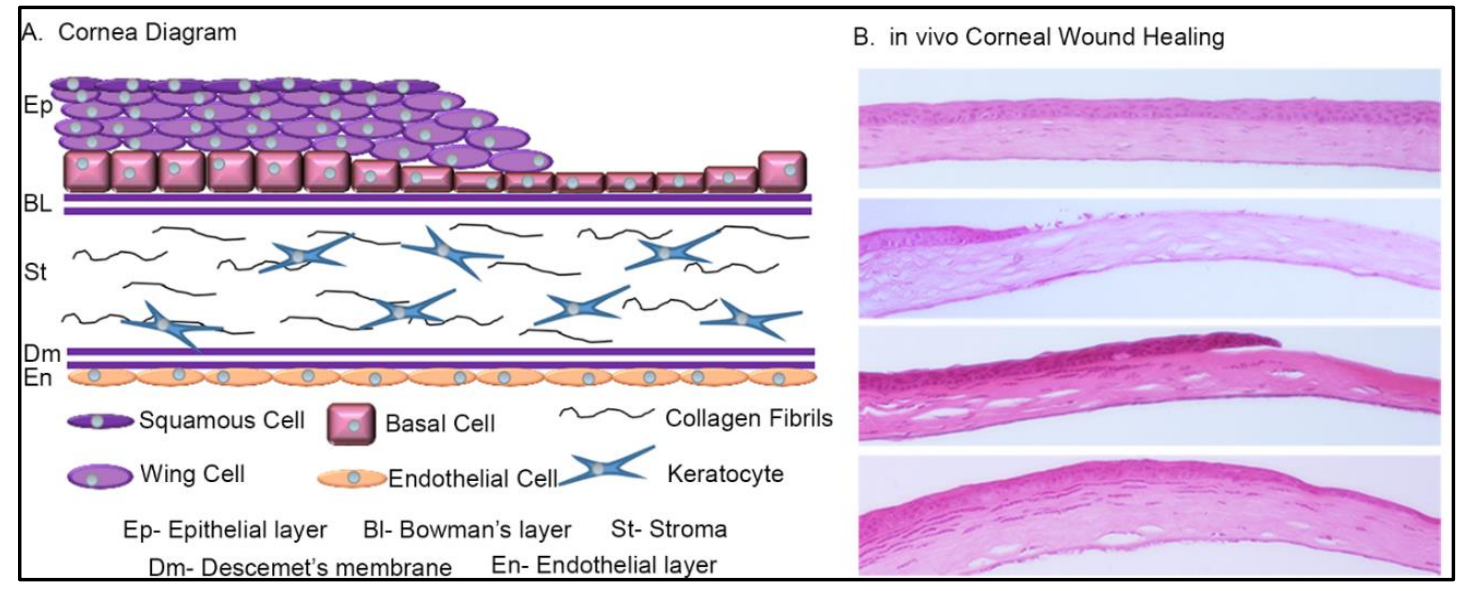

Figure 1. Corneal histology and wound healing

A) Layers of the cornea. The epithelium is the posterior layer of the cornea consisting of 5-7 layers of cells that control the passage of proteins into the stroma. The stroma mostly consists of highly organized collagen fibers with a sparse number of keratocytes that refract light, which is necessary for vision. The endothelium is a single layer of cells responsible for maintaining stromal fluid levels. B) H\&E stained cross sections of human epithelial ablated corneas in various stages of healing.

Excluding the skin, the eye is one of the most accessible organs in the body for in vivo studies and treatment. Due to its external location, treatments can be as simple as a drop or an injection, without invasive surgery to monitor changes. Since the corneal epithelium is the first structure to show trauma after exposure to diverse 
agents [14-17], it is critical to examine corneal epithelium for ocular pharmaceutical testing. EGFR is in high concentration in the cornea epithelium, and tear fluid contains EGF at concentrations close to the ligand's $\operatorname{Kd}$ for the receptor $[18,19]$. Therefore, studying EGFR mechanics after stimulation or inhibition is critical in producing new and better drugs for ocular therapies.

\section{ErbB Receptors}

\section{Structure and Function}

The ErbB family of receptor tyrosine kinases (RTKs) have well-established roles in developmental biology, tissue homeostasis, and cancer biology [20, 21]. All four family members [ErbB1 (Epidermal Growth Factor Receptor- EGFR), ErbB2, ErbB3, and ErbB4] share several structural and functional features including the size, the transmembrane orientation of the protein, and mechanism of activation. Each receptor has an extracellular region, a transmembrane helix and an intracellular region that includes the kinase domain and c-terminal tail [22].

The extracellular region of the ErbB-receptors consists of four domains that are responsible for ligand binding. Domains I and III are the ligand binding domains and II and IV are cysteine rich domains that play defining roles in ligand-dependent transactivation [23-25]. The four domains work in concert, fluctuating between a "closed" conformation and an "open" conformation that reveals a dimerization arm from domain II and a tethering arm in domain IV [26, 27]. Without ligand bound, the receptor prefers the "closed" conformation, which is anchored together by interactions between the dimerization and tethering arms within the molecule [28]. 
While ligand initiates most hetero- and homodimer interactions between receptors, preformed "inactive" dimers are present in the absence of ligand [28, 29].

Activation of ErbB receptors begins with ligand binding that induces receptor dimerization, transphosphorylation of cytoplasmic tyrosines, and docking of downstream effectors to those phosphotyrosines. Once ligand binds the receptor, the interaction between the arms is broken and the receptor toggles to a stable "open" conformation. Though the ErbB-receptors are structurally similar, each receptor has a specific set of ligands that are known to bind and activate the receptors. ErbB2 is an exception due to its open/active conformation and no known binding ligands [30]. Once the ligand binds domains I and III, the dimerization arm is exposed and the receptor is then able to either form homo- or heterodimers with the other ErbBfamily members [26, 31]. ErbB-receptors bind directly to each other instead of both receptors binding the same ligand; this is unique from other receptor tyrosine kinases $[26,31]$.

ErbB-family of receptors all consist of a transmembrane domain (TM) comprised of a single pass $\alpha$-helix. The TM in addition to the role as anchor of the receptor to the membrane [22], also plays a role in receptor activation and signal transduction by facilitating dimerization through interactions of GxxxG-like motifs at the $\mathrm{C}$ - and $\mathrm{N}$-terminal ends of the TM [32]. The C-terminal motif regulates receptor homodimers and the N-terminal plays a critical role in heterodimerization [33]. ErbB3 lacks the C-terminal GxxxG-like domain, which limits the ability to form homodimers after ErbB3-specific ligand stimulation [34]. 
The intracellular region of the ErbB-receptors is comprised of a juxtamembrane (JM) domain, a kinase domain (KD) and a tyrosine rich C-terminal tail. The activated KD facilitates the trans-phosphorylation of the C-terminal tyrosines after ligand binding and receptor dimerization [35]. Mutation or domain deletion of the JM causes termination of receptor phosphorylation [36-38], supporting the JM role in transphosphorylation. The ErbB-receptor KD has an N-lobe (head) containing a glycine rich loop and a C-lobe (tail) containing an activation loop and a catalytic loop [39]. The receptors arrange in an asymmetric head-to-tail conformation, which permits the transphosphorylation of tyrosines in the c-terminal tail as the $\mathrm{C}$-lobe of one receptor acts as a donor to the $\mathrm{N}$-lobe of the other receptor [37, 40, 41]. Initially, ErbB3 was thought to be kinase inactive [42, 43]. Later findings revealed ErbB3 has weak kinase activity [44], which could limit the kinase signaling potential. The now activated c-terminal tyrosines can interact with signaling molecules that have SH2 or PTB domains, which include adaptors, scaffolding proteins, signal transducers and transcription factors [45].

\section{ErbB Ligands}

\section{Structure and Function}

The ErbB family of receptors have eleven known ligands that bind to and activate specific receptors (Fig. 2). EGFR specific ligands include epidermal growth factor receptor (EGF), transforming growth factor-alpha (TGF-a), amphiregulin (AR), and epigen (EPN). Some of the EGF-like ligands bind multiple receptors. Heparin binding epidermal growth factor (HBE), and epiregulin (EPR) and betacellulin (BTC) bind and 
activate both EGFR and ErbB4, neuregulin (NRG) 1 and 2 activate ErbB3 and ErbB4. NRG 3 and 4 only activate ErbB4. All ErbB ligands contain an EGF domain that consists of six conserved cysteine residues that form three disulfide bonds during proper protein folding [46], which facilitates ligand:receptor binding. The consensus motif sequence for the EGF-like ligands is $\mathrm{CX}_{7} \mathrm{CX}_{4-5} \mathrm{CX}_{10} \mathrm{CXCX}$ where $\mathrm{X}$ is any amino

acid, the $\mathrm{C}$ is cysteine [47]. The presence and spacing of additional specific residues distinguishes this family from other proteins with EGF domains like Notch and Jagged I $[48,49]$.

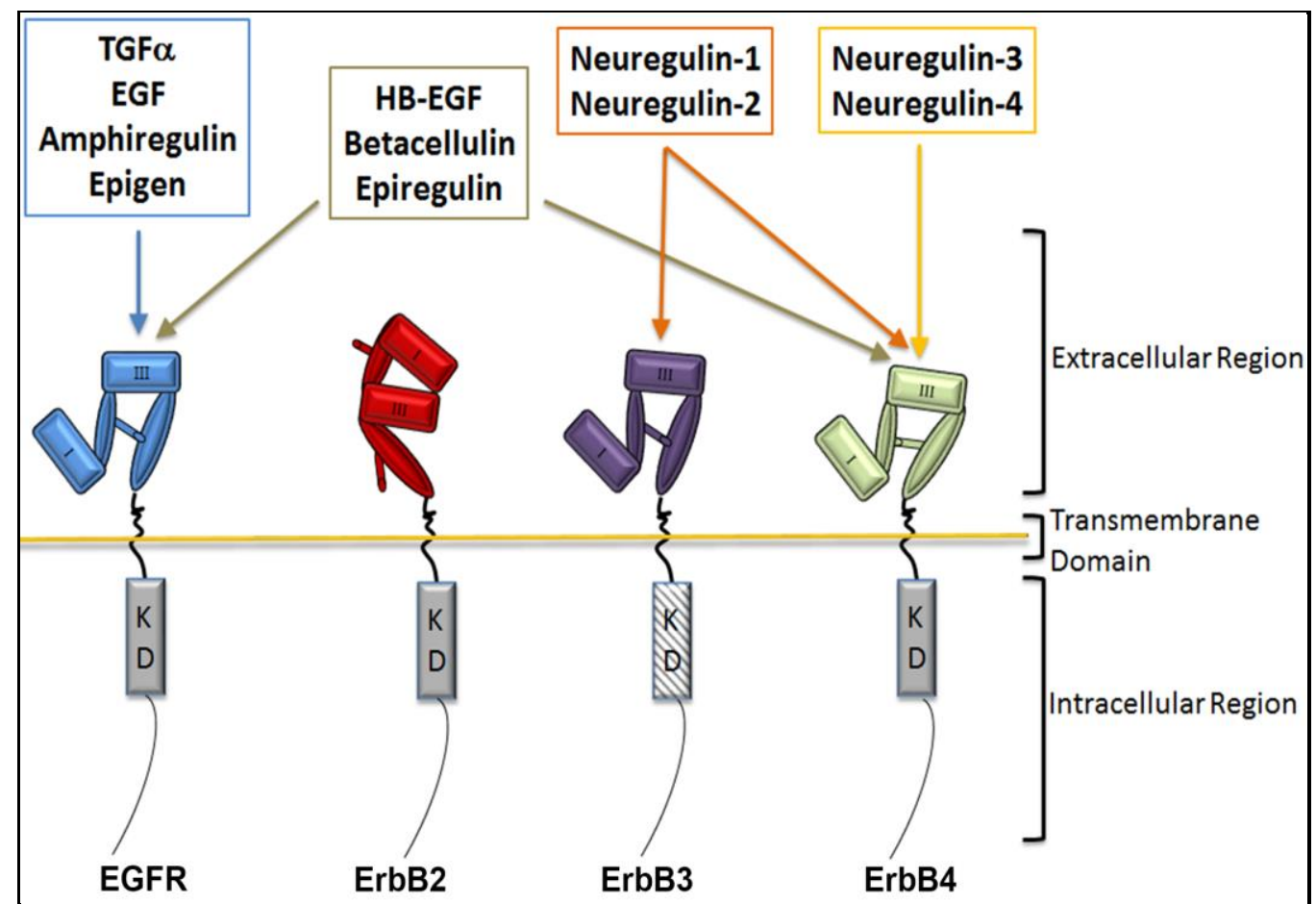

Figure 2. ErbB family of receptors

The ErbB family of receptors include ErbB1/EGFR, ErbB2, ErbB3 and ErbB4. Each receptor includes an extracellular region, a transmembrane domain, and an intracellular region. There are eleven known ligands specific to each receptor including EGF, TGFa, AR,

EGFR ligands are in a precursor form that is anchored to the plasma membrane. Juxtacrine signaling occurs between neighboring cells with ligands in this 
confirmation. Anchored ligands contain two extracellular sites specific to certain ADAM proteins that facilitate cleavage of the ligand. Once the protein is cleaved and in a soluble form, it then can signal by autocrine or paracrine signaling. Soluble EGFR ligands range in size from 6 to $11 \mathrm{kDA}$ and utilize the same binding site. Interestingly, each ligand can induce varying changes in cell physiology including enhanced development, migration, proliferation and differentiation $[2,19,50,51]$. The addition of EGF, TGF $\alpha$ and HBE to corneal epithelial cells, which induced greater corneal wound healing in vivo, reflects a part of the differential roles of EGFR ligands. Functional redundancy among ligands is indicative in initial studies reporting TGF $\alpha$, EGF and AR knockout mice do not show any tissue abnormalities [52]. While treatment with various ligands can illicit various changes in specific cell physiology, the redundancy in functionality maintains physiology after protein loss or inhibition. This redundancy can be important for consistency in cell function but is also a hindrance for receptor specific treatments for disease, like cancer due to compensatory mechanisms through unencumbered proteins. Further studies will be necessary to differentiate the degree of effect each ligand has on cell physiology when compared to the other ligands.

\section{Ligand:EGFR complexes}

Signaling events initiated by ligand induced EGFR:ligand complexes give rise to changes in cell physiology, and can be specific to which ligand is bound to the complex. While ligand binding to receptor initiates dimerization and activation, dimer partners and signaling outcomes can vary. Some factors that contribute to the 
ligand-initiated differences in cell physiology are binding characteristics (ligand and receptor), phosphorylation patterns of the receptor and trafficking of the receptor.

\section{Ligand specific binding}

EGFR ligands bind to the receptor with different affinity. The seven EGFR ligands are divided into two categories, those with strong affinity and those with weak affinity. Strong affinity ligands that bind with a lower affinity than $100 \mathrm{nM}$ include EGF, BTC, HBE, and TGF $\alpha$. Weak affinity EGFR ligands that bind at $>100 \mathrm{nM}$ include AR, EPR, EPN [53]. Saturation binding studies performed with EGF resulted in a concave up Scatchard plot, indicative of two binding affinities. There are two different explanations for this phenomenon: 1) the presence of two different populations of receptors [54] or 2) negative cooperativity is occurring [55, 56].

In a situation where there are two different populations of receptors, it is possible to calculate the affinity of each receptor population. The $\mathrm{K}_{\mathrm{d}}$ of EGF for the receptor is $\sim 0.3 \mathrm{nM}$ for high and $2 \mathrm{nM}$ for low receptors [18]. When two populations are present, activation is partially controlled by receptor density, where the higher density of receptors may accumulate in clathrin-coated pits or lipid rafts creating high affinity receptors [57]. It has been suggested that low levels of EGF can activate high affinity receptors and higher concentrations of ligand are needed for activation of low affinity populations [54]. Research has shown that the EGFRs are at an equilibrium mixture of all conformations, and the population exhibits binding characteristic that reflect the distribution of the receptor between high and low affinity forms [58]. External and internal binding of ligand, inhibitors or kinase mutations can shift the 
conformation equilibrium and shift the receptor from a low to high affinity receptor. Interestingly, each activated population of receptors induces different signaling cascades, with the high affinity population contributing the most biologically compelling signaling events $[54,59]$.

A negative cooperativity model predicts that binding of the first ligand will reduce the binding affinity of the second [60]. Previous and recent structural studies show evidence for a conformational change in the extracellular domain of EGFR upon ligand binding in Drosophila and in vitro. $[56,60]$. Therefore, this model supports the hypothesis that binding of the first ligand to a receptor would shift the extracellular domain of a dimer and impede the binding of a second ligand. This confirmation change would have a similar affinity as a liganded monomer (190-220 pM) whereas a dual liganded dimer has a lower affinity (2.9 nM) [55]. Supporting the negative cooperativity model, a study has shown that a single ligand molecule is sufficient to activate a dimer [61] even though ligand binding facilitates receptor dimerization [62].

\section{EGFR Signaling Mechanisms}

Once activated by ligand, the EGFR:ErbB complex initiates a labyrinth of signaling events. These events include phosphorylation of downstream proteins as well as ligand directed trafficking of the complex. EGFR autophosphorylation patterns are overlapping but have distinct signaling pathways. The choice of ligand appears to influence the fate of the receptor complex through binding differences, ligand size, stoichiometry changes or differential effector interactions. 


\section{Ligand specific phosphorylation}

The EGFR contains different tyrosine residues that once phosphorylated, provide a mechanism for ligand specificity, as each site allows for docking of specific effector molecules. Ligand differential phosphorylation was first shown using phosphopeptide mapping of ErbB4 [63] using mass spectrometry. This study shows that differential signaling begins with site-specific phosphorylation of the receptor designated by ligand choice. Ligand specific phosphorylation was further analyzed in a human epidermoid carcinoma cell line (A431) using EGF and TGF $\alpha$ to compare phosphorylation sites of ligands that activate EGFR [64]. Both ligands induced similar patterns of receptor tyrosine phosphorylation. However, some sites (Y992, S1142) varied in the intensity and duration of receptor phosphorylation. In a separate study, EGF and BTC induced different levels of receptor phosphorylation at tyrosine sites 1068 and 1173. These differences are associated with changes in downstream effectors including Shc, Ras and Raf proteins [65].

\section{Ligand specific trafficking}

The endocytic pathway can regulate the EGFR activity temporally and spatially. Trafficking of the EGFR can be altered based on the specific ligand that binds the receptor. A pivotal study comparing six EGFR ligands demonstrated that different ligands induced degradation, recycling or both using biochemical and immunofluorescent assays in HEp2 cells [66]. AR induced both rapid and slow recycling and EGF induced both slow recycling and degradation. TGF $\alpha$ and EPR cause rapid recycling of the EGFR back to the plasma membrane, allowing it to be activated 
again. BTC and HBE cause lysosomal degradation of the receptor. One of the main pathways of EGFR trafficking is clathrin-dependent endocytic trafficking. The mechanisms behind ligand differential trafficking are not fully understood, but one factor that differs between ligands is $\mathrm{pH}$ sensitivity. As the receptors travel through the endocytic pathway, they become involved with multiple compartments that become increasingly more acidic (Fig 3). Comparing a rapid recycling ligand TGF $\alpha$, and a slow recycling/degradation ligand EGF, 50\% of bound TGF $\alpha$ dissociates from the receptor at a $\mathrm{pH}$ of 6.8 compared to 5.0 for EGF [67]. The early endosome has a $\mathrm{pH}$ of $\sim 6.8$. When a receptor:ligand complex reaches this compartment, TGF $\alpha$ will dissociate and rapidly recycle, where an EGF bound ligand will stay bound to the complex to late endosome [68]. The recycling of the receptor also has physiological effects due to the repeated availability of the receptor after returning to the plasma membrane, which is reflected where treatment with $\mathrm{TGF} \alpha$ increases corneal epithelial migration when compared to EGF [69].

Degradation is another important trafficking event that regulates the receptor by down regulation. Degradation involves E3 ubiquitin ligase c-Casitas B-lineage Lymphoma (c-Cbl), which ubiquitylates the EGFR. c-Cbl is known to dock directly to tyrosine 1045 [70], and once the EGFR is ubiquitylated, it is marked for degradation. 


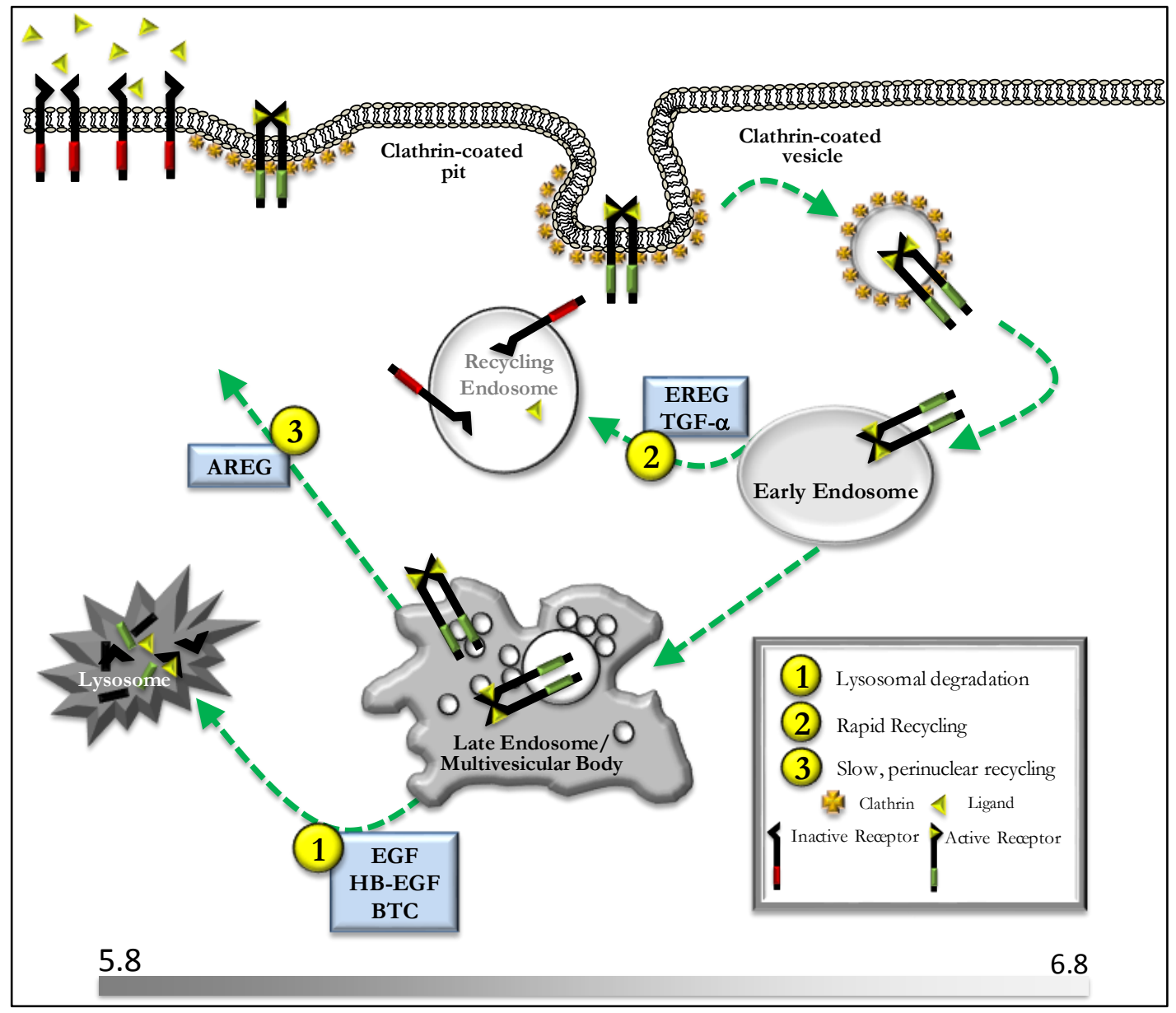

Figure 3. EGFR Endocytic Pathway- The EGFR undergoes ligand-dependent, clarhrinmediated endocytosis with physiological concentrations of ligand. When ligand binds the receptor, it dimerizes and the ligand-receptor complex translocate to a clathrin-rich region. This region invaginates and forms a clathrin-coated pit that pinches off and forms a clathrin-coated vesicle. Once the clathrin is shed from the vesicle, it fuses with an early endosome. The early endosome then matures into a late endosome that fuses with the lysosome where the receptor is degraded (1). The receptor also can be recycled back to the membrane via rapid (2) or slow (3) pathways.

\section{Betacellulin}

History and Physiology 
Since Stanley Cohen's discovery of EGF in 1962 and subsequent discovery of EGFR in 1970s, EGFR has been well characterized and described as the prototypical tyrosine kinase that is critical for tissue development and maintenance. However, regulation of the receptor is critical to maintaining the health and longevity of the tissue. Since the initial discovery of EGF, six additional EGFR specific ligands were found, including BTC [71], first reported as a mitogen in pancreatic $\beta$ cell tumors.

While BTC has similarities to the other EGFR ligands, it displays some unique properties [72]. BTC contains two cysteines that can form a fourth disulfide bridge, in addition to the six-cysteine consensus of the EGF motif. The human membranebound precursor form of BTC contains an Arg-Gly-Asp (RGD) sequence, suggesting an active role in mediating cell-cell interactions. In in vitro studies, BTC effects cell proliferation, differentiation, and survival, like other members of the EGF-like ligand family [72].

BTC is expressed in several tissues, but is found at high levels in the lung, kidney, and uterus [71]. Not surprisingly, high expression of BTC is also found in the pancreas where it seems to play a role in islet regeneration [73-75]. BTC is also found in milk [76], suggesting a role in the mammary gland or involvement in the development of the gastrointestinal tract of newborn mammals. Accelerated growth of gastrointestinal organs in rats occurred following the administration of recombinant BTC in rats [77]. Interestingly, mice lacking BTC had no visible physiology changes, no overt defects and no changes in viability or fertility [78]. This supports the functional redundancy within the EGF ligand family. 
Overexpression of BTC has been associated with pancreatic cancer, breast cancer, endometrium and endometrial cancer [79-81]. While the overexpression of BTC has been associated with various cancers, a BTC transgenic mouse model with ubiquitous overexpression of the ligand caused a plethora of phenotypic changes [82]. The BTC transgenic mice exhibited high early postnatal mortality, reduced body weight gain, and impaired longitudinal growth. Additionally, there were cataracts and abnormally shaped retinal layers as well as bone alterations leading to a domeshaped, round head that were hallmarks of BTC transgenic mice. Pulmonary pathology primarily characterized by alveolar hemorrhage, thickening of the alveolar septa, intraalveolar accumulation of hemosiderin-containing macrophages, and nodular pulmonary remodeling all proved to be the most lethal characteristic of overexpression of BTC.

An in vitro study indicated BTC as the most efficacious mediator in corneal wound healing, including cellular migration [19], but in vivo studies revealed EGF as the most effective corneal wound healing ligand. Clinical studies using EGF as a treatment of wound healing showed varying results in exogenous treatment with EGFR ligands [83-86]. This variability could be a result of endogenous ligand variability, the extent of the wound or the health of the eye and patient.

\section{Binding and Dimerization}

The ability of EGF-like ligands to bind to various members of the ErbB receptor family complicates the study of ligand initiated cross-linked signaling pathways. HBEGF and BTC are the only two EGFR ligands that can induce homodimers of EGFR and 
ErbB4 [72]. Betacellulin is unique because it binds only two receptors, but can ubiquitously activate all the ErbB family of receptors. While it is well accepted that BTC binds and activates both EGFR and ErbB4, the activation and binding of ErbB3 is still controversial. Studies have shown that BTC does not bind nor activate ErbB3 [53, 87, 88], reported weak binding and activation $[72,89]$, and finally, there is evidence of robust activation [90, 91]. In general, BTC is not considered an ErbB3 ligand due to the availability of other receptors for heterodimers when the receptor is activated, or ligand concentrations are above physiologically relevant levels.

No known ligand binds to the ErbB2 receptor, but it is recognized as the most likely heterodimer partner to all the ErbB ligands. ErbB2:ErbB3 heterodimers have been labeled as the most oncogenic pairing of all the ErbB family of receptors due to their involvement in cell proliferation [89, 91]. Several studies show that ErbB3 cannot be activated without ErbB2, but these studies focus on the ErbB3 specific ligands Neu1 and Neu2 [92, 93] or cancer biology [94].

Although ErbB3 activation and dimerization is not well understood, the basic physiology of the ErbB-receptors and ligands is well analyzed. The next step in understanding the ErbB-family signaling and regulation will include studies that directly compare each ligand to the others. This study is important to dissecting which ligands initiate specific physiology changes, and eventually, which pathways can compensate after ErbB antagonist treatments. 


\section{CHAPTER II 1}

BETACELLULIN BIASES THE EGFR TO DIMERIZE WITH ERBB3

\section{Introduction}

The ErbB family of receptor tyrosine kinases (RTKs) have well-established roles in developmental biology, tissue homeostasis, and cancer biology [20, 21]. All four family members [ErbB1 (Epidermal Growth Factor Receptor- EGFR), ErbB2, ErbB3, and ErbB4] share a number of structural and functional features including their size, transmembrane orientation of the protein, and mechanism of activation. Activation of ErbB receptors begins with ligand binding that induces receptor dimerization, transphosphorylation of cytoplasmic tyrosines, and docking of downstream effectors to those phosphotyrosines. These activated effectors induce biochemical changes that lead to modifications in cell biology. Each ErbB family member is unique in its activating ligands, degree of kinase activity, and cadre of downstream effectors. These features confer receptor-specific biochemical signals, which regulate the resulting cell biology.

Receptor specific ligands initiate ErbB RTK signaling. There are 13 known ligands for the ErbB family of proteins, each encoded by a distinct gene [95]. These

\footnotetext{
${ }^{1}$ Reprinted with permission of the American Society for Pharmacology and Experimental Therapeutics
} 
ligands differ in their tissue distribution as well as their rates of association and dissociation to each receptor. Not only do ligands drive the specificity of receptor:effector interactions, but also the duration and magnitude of effector response through differences in membrane trafficking $[96,97]$. Ultimately, the ligand specific mechanisms influence the cellular and physiological responses.

Despite the appreciation that ligands can induce receptor-specific signaling events, the molecular basis for these differences are not always clear due to the intrinsic barriers to ligand analysis. Knockdown of the EGFR results in embryonic lethality in mice, or death shortly after birth, highlighting its role in embryonic development [98]. In contrast, mice engineered to individually knock out epidermal growth factor (EGF) [52], transforming growth factor- $\alpha$ [99], epigen [100], heparin binding-EGF [78], betacellulin (BTC) [78], or amphiregulin [52] reveal no lethal ligand-specific phenotypes and all mice were viable and fertile. More subtle phenotypes include minor defects, such as altered epithelial tissue homeostasis, mammary tissue development, or a "wavy" phenotype of the hair [101]. The distinct knockout phenotypes indicate ligand-specific roles in tissue development and homeostasis. Absence of lethality when a single ligand is knocked out is consistent with functional redundancy among the ligands for the EGFR's most critical functions. While the overlapping roles of the ligands are likely beneficial to animals, analysis of the physiological contributions of individual ligands is difficult. In order to circumvent the limitations of in vivo analysis we, like many others, have turned to cell biology and biochemical assays to understand ligand-specific signaling. 
Among the endogenous EGFR ligands, BTC is one of the most poorly understood. It was first identified as a secreted growth factor from pancreatic $\beta$-cell insulinomas [71, 102], and has been implicated in a number of physiological processes, including $\beta$-cell proliferation [74], keratinocyte proliferation [103], and angiogenesis [104]. In endometrial, liver, and pancreatic cancers, BTC levels are elevated $[79,80,105]$. BTC is a dual-specificity ligand that binds both EGFR and ErbB4 [106, 107]. It has been argued that BTC also binds ErbB3 [108]. The most compelling evidence for this comes from 32D myeloid progenitor cells that lack endogenous ErbB RTKs. When ErbB2 and ErbB3 are exogenously expressed, there is ErbB2 and ErbB3 tyrosine phosphorylation and increased ${ }^{3} \mathrm{H}$-thymidine incorporation (DNA synthesis) [91]. However, a more systematic analysis used ErbB RTKs expressed individually or in pairs; these studies demonstrated that measurable binding of BTC only occurs when EGFR and ErbB4 are expressed [53].

BTC-null mice are viable and exhibit no overt phenotypes or problems with fertility; however, the life span of these mice is reduced [78]. While the lack of BTC demonstrates a positive role in cell biology, overexpression of BTC causes abnormal hair follicle development [104], increased glucose tolerance [109], and altered corneal development [82]. In corneal epithelial cells, BTC is more efficacious than EGF in mediating wound healing [19]. Despite evidence that BTC enhances wound healing under both physiological and pathological conditions, the molecular mechanism by which BTC enhances this process is unclear. These data illustrate the long-standing, inherent confusion regarding BTC-mediated signaling, and the need for a unifying model. 
In this study, we found that BTC is a better mediator of cell migration than EGF, despite a lower affinity for and reduced phosphorylation of the EGFR [110]. The reduced receptor phosphorylation is due to the EGFR's formation of heterodimers with the kinase impaired ErbB3. Biochemical evidence for these heterodimers comes from the ability of BTC to promote ErbB3 phosphorylation in the absence of ErbB2. Cell biological evidence of EGFR:ErbB3 heterodimers is visualized with proximity ligation assays. When ErbB3 signaling is antagonized or depleted using an ErbB3 antibody MM-121 [111] or siRNA, cell migration is reduced more in response to BTC than EGF; further indicating BTC mediates migration through ErbB3. Together, these data provide a new model in which a ligand can bias dimerization partners of the EGFR and affect cell physiology [112].

\section{Experimental Procedures}

Cell lines - hTCEpi cells were obtained from Geron Corp. (Menlo Park, CA). Human corneal epithelial cells were immortalized by the stable transfection of human telomerase reverse transcriptase [113]. Cells were grown in growth media (Defined Keratinocyte with growth supplement; Invitrogen, Carlsbad, CA) at $37^{\circ} \mathrm{C}$ and were maintained at $5 \% \mathrm{CO}_{2}$. MDA-MB-468 cells were acquired from the ATCC. Cells were maintained in growth media [Dulbecco's Modified Eagle Medium (DMEM)] supplemented with 10\% Fetal Bovine Serum (FBS), 1\% penicillin, 1\% streptomycin, and $2 \mathrm{mM}$ glutamine all acquired from Life Technologies (Grand Island, NY). Cells were maintained at of $37^{\circ} \mathrm{C}$ in $5 \% \mathrm{CO}_{2}$. 
Materials - EGF, BTC, and NRG4 were purchased from Prospec-Tany TechnoGene Ltd (Rehovot, Israel). MM-121 (seribantumab) was a kindly provided by Merrimack Pharmaceuticals, Inc, (Cambridge, MA) [111]. All other chemicals were purchased from Sigma-Aldrich unless otherwise noted.

Single cell growth assay - hTCEpi cells were plated at a density of 30 cells/well in a 12 well tissue culture dish in low serum media (25\% growth media and $75 \%$ serum free media). Cells were grown to the eight cell stage then treated with EGF or BTC [1.6 nM] or no ligand. Photographs of the cell colonies were taken every 24 hours. At each time point, the number of cells per colony were counted and the area the colony covered was measured using Image J software [114].

Competition binding - All radioligand binding experiments used binding buffer (DMEM (without bicarbonate), 10mM NaHEPES, 0.1\% BSA, pH 7.4). Confluent 12well dishes of hTCEpi cells were incubated with varying concentrations of cold ligand (EGF, BTC, NRG4) and 125I-EGF (Perkin Elmer Life Sciences, catalog no. NEX160; specific activity $150-200 \mu \mathrm{Ci} / \mu \mathrm{g}, \sim 10,000 \mathrm{cpm} / 10 \mu \mathrm{l})$. Cells were incubated on ice for 2 hours allowing a steady state binding while preventing membrane trafficking. Cells were washed 4 times with radioligand binding buffer, solubilized in $0.1 \%$ SDS $/ 0.1 \mathrm{~N}$ $\mathrm{NaOH}$ and radioactivity level of each sample was determined using a Beckman Coulter gamma counter (Brea, CA). Data are plotted as the percentage of maximal radioactivity as determined from cells with no competitive ligand added. IC50 values were calculated using a one-site model using GraphPad Prism 5.0 (La Jolla, CA). 
pH dissociation binding - Confluent 12-well dishes of hTCEpi cells were incubated with ${ }^{125}$ I-EGF or ${ }^{125}$ I-BTC $(\sim 10,000 \mathrm{cpm} / 10 \mu \mathrm{l})$. Cells were incubated on ice for 2 hours allowing a steady state distribution of the ligands. The $\mathrm{pH}$ of radioligand binding buffer was adjusted with $\mathrm{NaOH}$ or $\mathrm{HCl}$ to bring the buffer to the desired $\mathrm{pH}(2-8)$. $\mathrm{pH}$-adjusted buffer was used to wash the cells to remove excess ligand and dissociate the ligand from the receptor. Cells were solubilized in $0.1 \% \mathrm{SDS} / 0.1 \mathrm{~N} \mathrm{NaOH}$ and the associated radioactivity in each sample was determined using a Beckman Coulter gamma counter. Data are plotted as the average $( \pm$ S.E.M.) percentage of radioactivity relative to maximal binding.

Western blot with phospho-specific antibodies - hTCEpi cells were washed twice with PBS pH 7.4 and incubated with serum-free KSFM for $2 \mathrm{~h}$. Cells were treated with the indicated ligand concentration at the indicated time. Treated cells were subjected to two quick washes with PBS pH 7.4, equilibrated to $4^{\circ} \mathrm{C}$ on ice. Cells were harvested in RIPA buffer (150 mM NaCl, 1\% Nonidet P-40, 0.5\% deoxycholate, 0.1\% SDS, $50 \mathrm{mM}$ Tris, pH 8.0, $10 \mathrm{mM}$ sodium pyrophosphate, $100 \mathrm{mM}$ sodium fluoride) supplemented with $2 \mathrm{mM}$ Phenylmethylsulfonyl fluoride (PMSF), solubilized with end over end rotation for $10 \mathrm{~min}$ at $4^{\circ} \mathrm{C}$. Insoluble material was removed by centrifugation for 10 min at $4^{\circ} \mathrm{C}$ and maximum speed $(21,130 \mathrm{rcf}$ ) in an Eppendorf 5424R (Hamburg, Germany). Equivalent amounts of cell lysate were resolved by SDS-PAGE and transferred to nitrocellulose. The indicated proteins were immunoblotted using the following antibodies: EGFR (SC-03) and EGFR (A-10) antibodies obtained from Santa Cruz Biotechnology (Dallas, TX), site specific phospho-EGFR antibodies (pY992, pY998, pY1045, pY1068, pY1148, and pY1173) were from Cell Signaling (Danvers, 
MA), $\alpha$-tubulin antibodies were from Sigma-Aldrich (St. Louis, MO). Following incubation with the appropriate HRP-conjugated secondary antibody, immunoreactive proteins were visualized with ECL and a Fotodyne Imaging system (Hartland, WI).

Immunoprecipitations - Cell lysates (500 $\mu \mathrm{g}$, see "Western Blot") were incubated with either a pool of phospho-tyrosine antibodies (pY20, sc-508; pY99, sc-7020 from Santa Cruz Biotechnology, Santa Cruz, CA and 4G10, 05-321 from EMD Millipore, Billerica, MA) or ErbB3 antibodies (sc-285, sc-7390, sc-415, Santa Cruz Biotechnology, Santa Cruz, CA)(HER3/ErbB3 (D22C5) XP, Cell Signaling) while rotated end over end at $4{ }^{\circ} \mathrm{C}$ overnight. Protein A/G agarose beads (Santa Cruz Biotechnology, Dallas, TX) washed with RIPA buffer were added and rotated end over end at $4^{\circ} \mathrm{C}$ for 2 hours. Lysates were centrifuged and a sample of the supernatant was kept as pass through (PT), the rest discarded. Then, RIPA buffer was used to wash the beads three times. To elute the protein from the beads, SDS sample buffer was added to the samples and heated to $100^{\circ} \mathrm{C}$ for three minutes. The immunoprecipitates were divided into thirds, separated by SDS-PAGE, transferred to nitrocellulose, and detected with the indicated antibody EGFR and PY99 (Santa Cruz Biotechnology, Dallas, TX); ErbB2 and ErbB3 (Cell Signaling); ErbB3 (Santa Cruz Biotechnology, Dallas, TX, Cell Signaling), as described previously.

PLA Proximity Ligation Assay (PLA) - hTCEpi cells were plated on $\mathrm{NaOH}$ cleaned $12 \mathrm{~mm}$ round \#1 coverslips in a 24 -well plate and grown to $70-80 \%$ confluency. Serumstarved cells were treated with media, EGF $(16 \mathrm{nM})$, or BTC $(16 \mathrm{nM})$ at $37^{\circ} \mathrm{C}$ for 15 
min. Coverslips were washed with $\mathrm{PBS}^{++}\left(\mathrm{PBS} \mathrm{pH} 7.4 / 0.25 \mathrm{M} \mathrm{CaCl}_{2} / 0.25 \mathrm{M} \mathrm{MgCl}_{2}\right.$ ) and fixed with $4 \%$ paraformaldehyde/PBS ${ }^{++}$for $5 \mathrm{~min}$ on ice and $15 \mathrm{~min}$ at room temperature. Cells were permeabilized with $0.1 \%$ saponin $/ 0.5 \%$ fetal bovine serum/ $/ \mathrm{PBS}^{++}$for $15 \mathrm{~min}$, washed 3 times in $\mathrm{PBS}^{++}$. EGFR homodimers and EGFR:ErbB3 heterodimers were detected using Proximity Ligation Assay kit (DuoLink, Sigma Aldrich) according to manufacturer's directions. Primary antibodies EGFR (E114, RabMAb Abcam) and ErbB3 (2F12, Thermo Scientific) were used independently and jointly as indicated in experiments. Fluorescence images and quantification were acquired using a Nikon Eclipse Ti-E widefield microscope using Nikon NIS Elements software (Nikon, Melville, NY).

Transwell migration assay - 100,000 hTCEpi cells in serum- free media (Keratinocyte Defined Media without growth supplement, $100 \mu \mathrm{L}$; Invitrogen) with or without 170 $\mu \mathrm{g} / \mathrm{ml} \mathrm{MM}-121$. were plated in the upper chamber of an $8 \mu \mathrm{m}$ polycarbonate membrane, $6.5-\mathrm{mm}$ insert (Corning, Inc., Corning, NY) for 2 hours at $37^{\circ} \mathrm{C}$. Following incubation, the lower chamber contained $600 \mu \mathrm{L}$ serum-free media containing the indicated concentrations of growth factor with or without MM-121 (seribantumab, a gift of Merrimack Pharmaceuticals, Cambridge, MA). Cells were allowed to migrate for 16 hours at $37^{\circ} \mathrm{C}$ in $5 \% \mathrm{CO} 2$. Migrated cells were determined by fixing the cells in methanol, staining in Giemsa, and counting the migrated cells under a microscope (TE-2000; Nikon, Tokyo, Japan) with a 60X objective[115].

siRNA - The siRNA were obtained from the following sources: scramble control siRNA (siCON), EGFR and ErbB2 were acquired from IDTDNA (Coralville, IA), ErbB3 Silencer 
Select was acquired from ThermoFisher Scientific, Waltham, MA). hTCEpi cells were transfected with the indicated siRNA by Amaxa electroporation as described previously [116]. Cells were allowed to recover for 48 hours. Cells were assayed by western blot for knockdown efficacy, phosphorylation of receptors or cell migration as described in materials and methods.

Statistical analyses - Statistical tests are indicated in the figure legends and were performed using GraphPad Prism 5.0 (La Jolla, CA).

\section{Results}

\section{BTC induces more cell migration than EGF}

Our previous studies identified BTC as a more efficacious mediator of in vitro corneal epithelial wound healing than EGF [19]. Corneal epithelial wound healing is a multi-faceted process that includes cell migration and proliferation [117]. The first goal for understanding the molecular basis for BTC's enhanced activity was to determine if the ligand was augmenting cell migration, cell proliferation, or both processes. To assess ligand effect on proliferation and migration, hTCEpi cells were plated as single cells and cultured in media alone or media supplemented with EGF or BTC. The same colony was photographed over 72 hours (Fig 4A). From these images, the number of cells and their total area was determined (Fig 4B, 4C). Cells grown in the presence of BTC covered a larger area of the dish as compared to those grown in EGF or media alone indicating the BTC-treated cells were more migratory. Importantly, treatment with EGF increased the number of cells. 
To supplement that assay, a Transwell assay was used to directly measure cell migration in response to the growth factors (Fig 4D). BTC had a 6-fold increase in cell migration as compared to 4-fold increase with EGF. Together, these assays demonstrate that BTC more efficaciously promotes cell migration as compared to EGF.

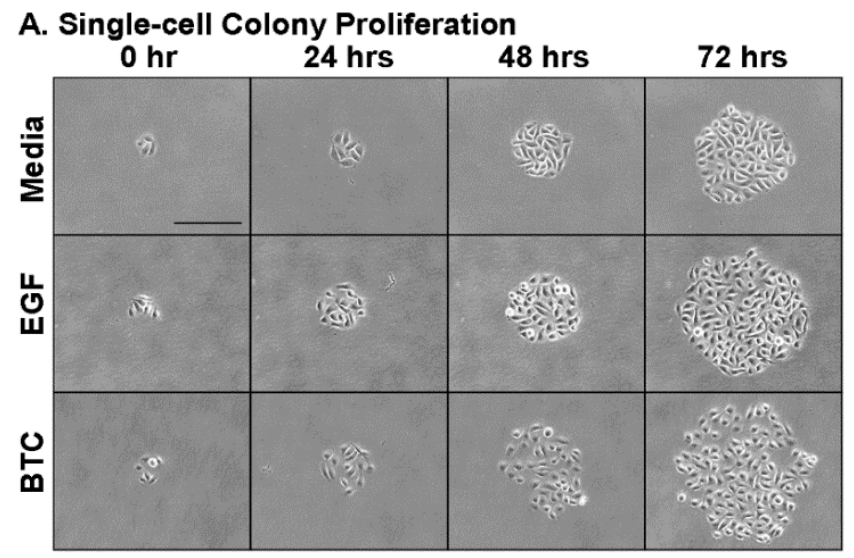

B. Number of Cells

\section{Area/Cell}

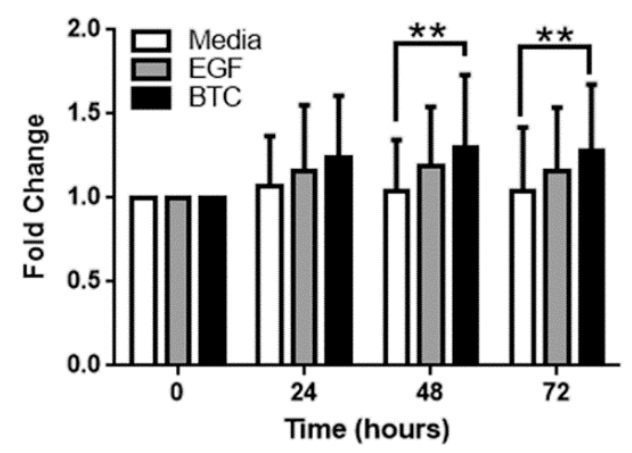

D. Quantification of Transwell migration

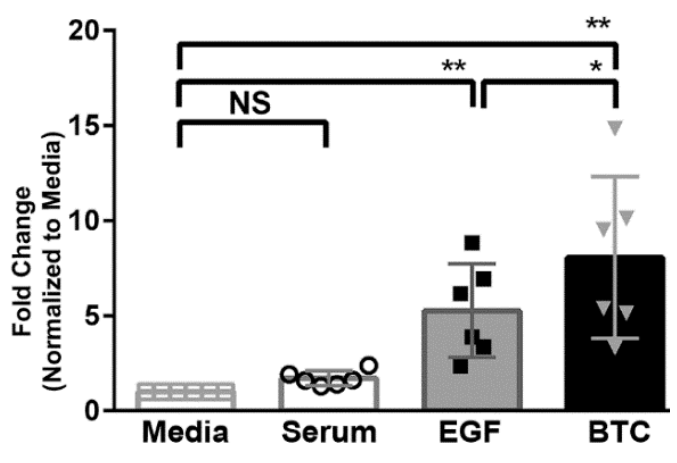

Figure 4. BTC is a more efficacious activator of cell migration than EGF. A-C) hTCEpi cells were plated as single cells (30 cells/35 mm dish) in media alone, $1.6 \mathrm{nM} \mathrm{EGF}$, or 1.6 nM BTC (Peterson, JL). A) Once cell colonies formed, they were imaged at 24 hour intervals for 72 hours. Shown are representative data from an experiment repeated three times ( $n=3-4$ experiments, $\sim 25-70$ colonies for each condition). Scale bar $=200 \mu \mathrm{m}$. B) Data from three separate experiments were plotted as average \pm S.D. fold change as number of cells per colony. C) Data from three separate experiments were plotted as average \pm S.D. fold change in area per cell. D) hTCEpi cell migration was measured using a Transwell assay after migrating for 16 hours as described in Experimental Procedures (Rush, JS). Cells were incubated in serum free media with no additions (Media), serum (Serum), 1.6 nM EGF, or 1.6 nM BTC. Plotted are the fold changes in cell migration (relative to serum free media) for each condition $(n=6)$. Data were analyzed using a twoway ANOVA with Tukey's post-hoc analysis. ${ }^{*}=\mathrm{p}<0.05$ and $^{* *}=\mathrm{p}<0.01$. 
BTC binds EGFR with lower affinity.

BTC is universally accepted to bind both EGFR and ErbB4 $[90,118]$, but others report that BTC can bind/activate ErbB2 and ErbB3 as well [87, 91]. hTCEpi cells do not express ErbB4 [19], so we restricted our focus to the EGFR. To determine if EGF and BTC were binding the same receptor, we performed an ${ }^{125}$ I-EGF competition binding assay. EGF, BTC, and Neuregulin 4 (NRG4) as a negative control, were used to compete for radiolabeled EGF (Fig $5 \mathrm{~A}$ ). EGF ( $\mathrm{IC}_{50}=\sim 2 \mathrm{nM}$ ) was able to compete for 125I-EGF binding with a 30-fold higher affinity than BTC $\left(\mathrm{IC}_{50}=\sim 60 \mathrm{nM}\right) ; 100 \mathrm{nM}$ NRG4 was unable to displace 125I-EGF binding, consistent with its role as an ErbB4 specific ligand (Fig 5A). These data indicate that EGF and BTC compete for the same binding site and BTC has a lower affinity for the EGFR.

Next, we examined whether EGFR binding of BTC and EGF, had differing sensitivities to $\mathrm{pH}$. As the ligand:receptor complex progresses through the endocytic pathway, it moves through an increasingly acidic environment. Ligand binding is one of the factors that determines if the receptor recycles back to the plasma membrane or is targeted to the lysosome. Approximately 50\% of bound ${ }^{125}$ I-EGF dissociated at pH 5.8, whereas a pH of 4.3 was required to dissociate $50 \%$ of the bound ${ }^{125}$ I-BTC (Fig $5 B)$. These values led to the prediction that $\sim 50 \%$ of EGF:EGFR complexes will dissociate in the early endosome [pH $~ 5.9-6.8$ [119]], whereas, the BTC:EGFR is not predicted to have appreciable dissociation, even in the lysosome [pH 4.5-5.0 [119]]. 


\section{A. 125 I-EGF Competition binding}
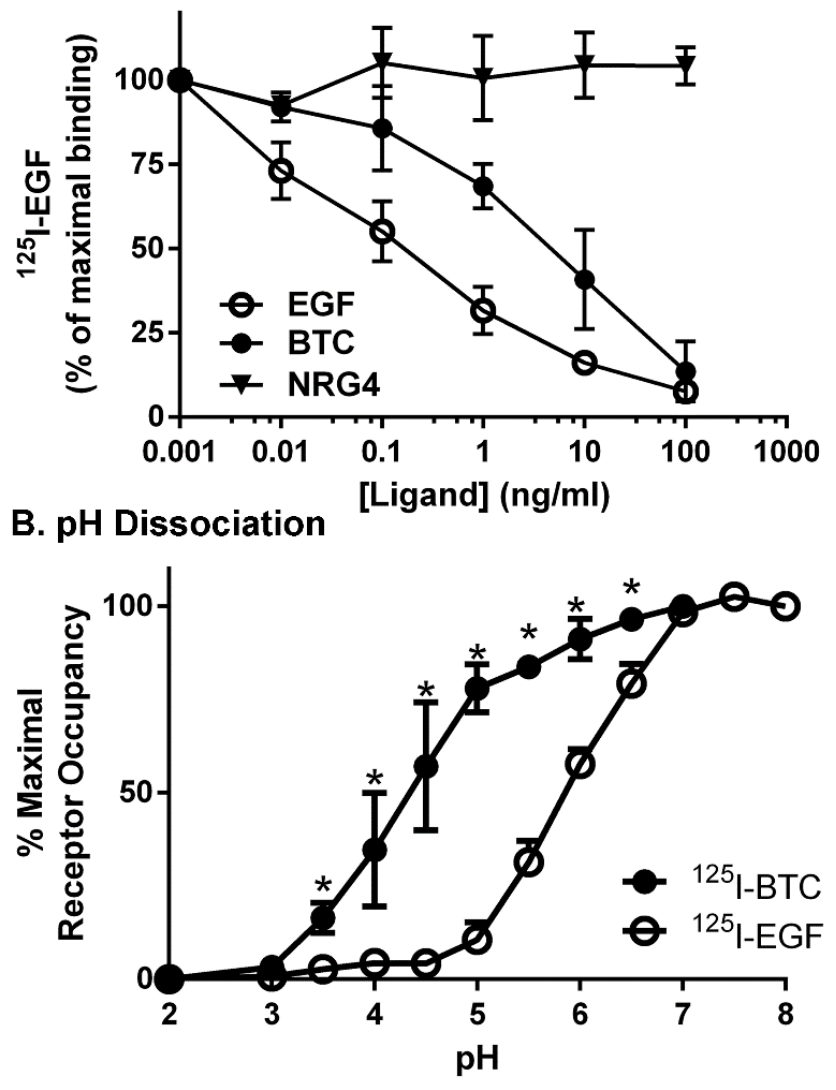

Figure 5. BTC and EGF bind EGFRs with different affinities and pH sensitivities. A) 125I-EGF competition binding using varying concentrations of EGF, BTC, or NRG4 as indicated. B) pH sensitivity of 125 I-EGF and ${ }^{125}$ I-BTC binding. Cells were incubated with radioligand at $\mathrm{pH} 7.4$ and $4{ }^{\circ} \mathrm{C}$ until steady-state binding was achieved. Cells were then incubated in binding buffer at varying $\mathrm{pH}$ at $4^{\circ} \mathrm{C}$ for 30 minutes, then washed three times in ice cold buffer of the same $\mathrm{pH}$. Cells were solubilized and associated radioactivity was measured. For (A-B), data are plotted as the percent of maximal radioligand binding (average \pm S.D., $n=3$ ) (Peters JL).

BTC induces less EGFR phosphorylation but more ErbB3 phosphorylation

Consistent with the reduced affinity, BTC was a weaker activator of EGFR, as compared to EGF. Using ligand concentrations that produced maximal cell migration [19], a time course of tyrosine phosphorylation was used as a read-out of EGFR activity (Fig 6). hTCEpi cells treated with BTC as compared to those treated with EGF had reduced EGFR phosphorylation at all four of the tyrosine residues examined (Fig 
6A). Similar trends were observed in MDA-MB-468 cells, a metastatic breast cancer cell-line with comparable levels of EGFR (Fig 7).

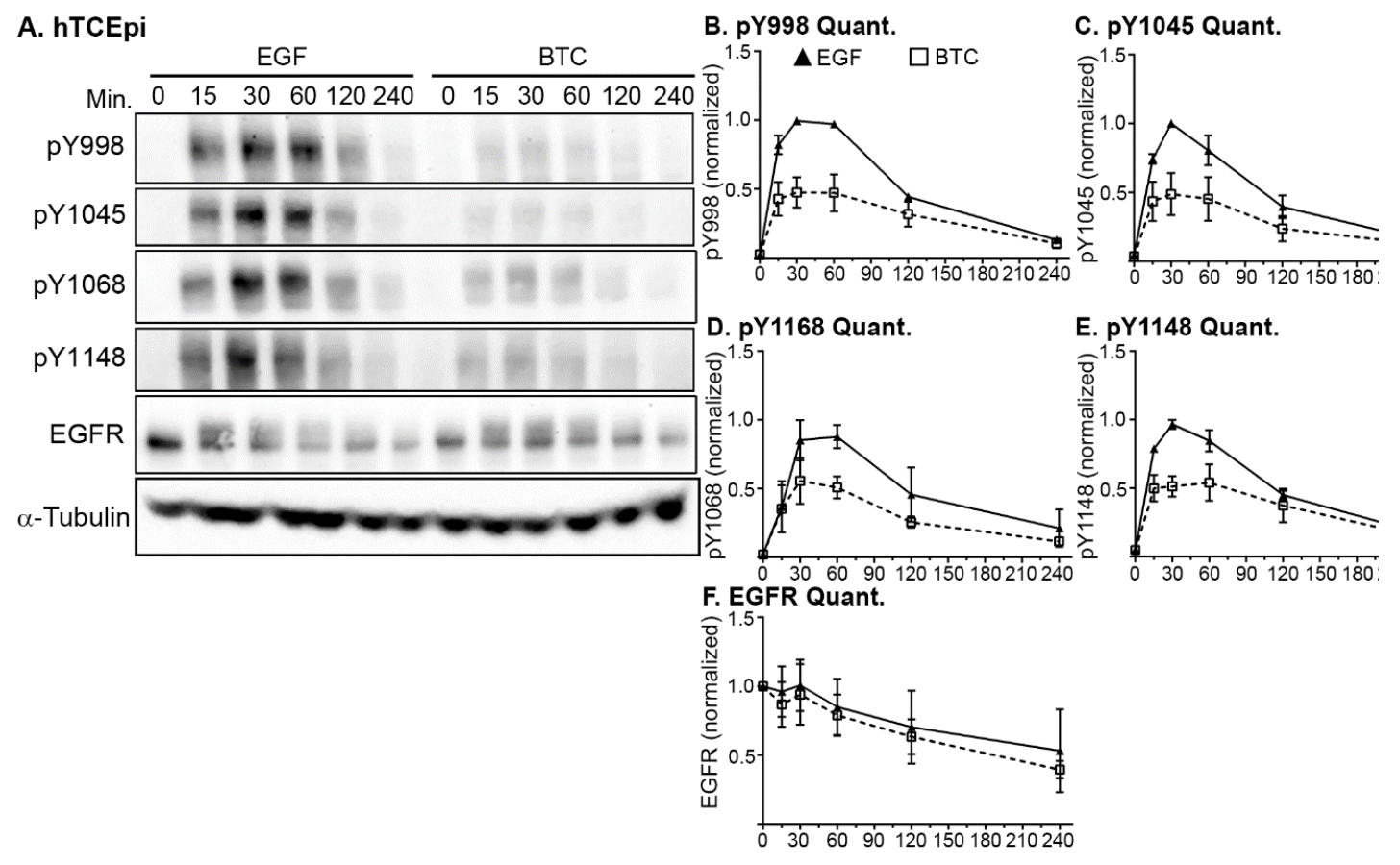

Figure 6. BTC is a less efficacious activator of EGFR phosphorylation in hTCEpi cells. Cells were treated with $1.6 \mathrm{nM}$ EGF or $1.6 \mathrm{nM}$ BTC for the indicated times. Cell lysates were prepared and immunobloted with the indicated EGFR phosphotyrosine specific antibodies (pY998, pY1045, pY1068, pY1148), total EGFR, or $\alpha$-tubulin. A) hTCEpi cell representative blots from three experiments (Peterson JL). B-F) Western blots quantified using ImageJ software. Phosphotyrosine blots were normalized to the 30 min timepoint, total EGFR is normalized to untreated EGFR levels (Rush JS). 

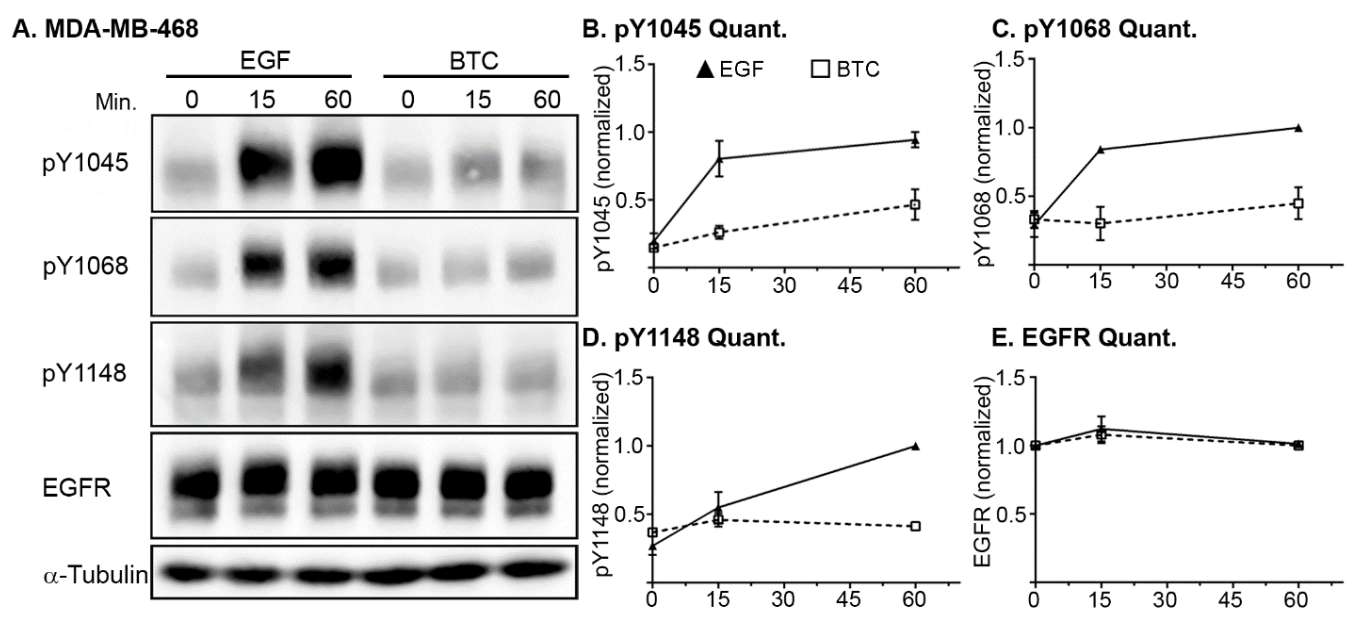

Figure 7. BTC is a less efficacious activator of EGFR phosphorylation in MDA-MB468 cells. Cells were treated with 1.6 nM EGF or $1.6 \mathrm{nM}$ BTC for the indicated times. Cell lysates were prepared and immunobloted with the indicated EGFR phosphotyrosine specific antibodies (pY998, pY1045, pY1068, pY1148), total EGFR, or $\alpha$-tubulin. A) MDAMB-468 cell representative blots from three experiments. B-E) Western blots from A) were quantified using NIH ImageJ software. Data are presented as a ratio of each treatment to the most abundant protein.

The decrease in EGFR phosphorylation led us to an alternative explanation. We hypothesized that EGF promoted EGFR homodimers, whereas BTC preferentially formed EGFR:ErbB3 heterodimers. The model accounts for the observation that 1) the ligands can compete for binding with one another $[53,120], 2)$ the EGFR:ErbB3 heterodimers would have reduced EGFR phosphorylation due to ErbB3 being kinase impaired [42], and 3) ErbB3 activation is associated with induced proliferation and migration [121-123].

To test whether BTC could differentially signal through other ErbB receptors, we examined receptor phosphorylation (Fig 8). hTCEpi cells were treated with media alone, or media supplemented with EGF or BTC. Denatured cell lysates were immunoprecipitated with an anti-phosphotyrosine antibody and probed for the presence of the three endogenous ErbB receptors (Fig 8A). BTC treatment led to 
decreased phosphorylation of EGFR and ErbB2 when compared to EGF, whereas only BTC treatment resulted in significant ErbB3 phosphorylation (Fig 8D). Significant ErbB3 phosphorylation by BTC was also observed when cell lysates were immunoprecipitated using an ErbB3 antibody and immunoblotted with an antiphosphotyrosine antibody (Fig 8B, 8E).

hTCEpi cells were transduced using ErbB2-specific shRNA to examine the possibility of ErbB2 involvement in ErbB3 phosphorylation. BTC-mediated activation of ErbB3 is unaffected by the loss of ErbB2 (calculated to be $86 \%$ knockdown), further indicating that ErbB2 is dispensable in BTC activation of ErbB3 (Fig 8C, 8F). To determine whether these observations were specific to hTCEpi cells, we treated MDA-MB-468 cells with EGF and BTC, and then immunoprecipitated phosphorylated tyrosines and immunoblotted for the same three ErbB receptors available in hTCEpi cells (Fig 9A-D). MDA-MB-468 cells express EGFR and ErbB3, but do not express detectable levels of ErbB2 or ErbB4 [124](Figure 9A-D). As with the hTCEpi cells, BTC treatment resulted in less EGFR tyrosine phosphorylation, and induced ErbB3 tyrosine phosphorylation. 

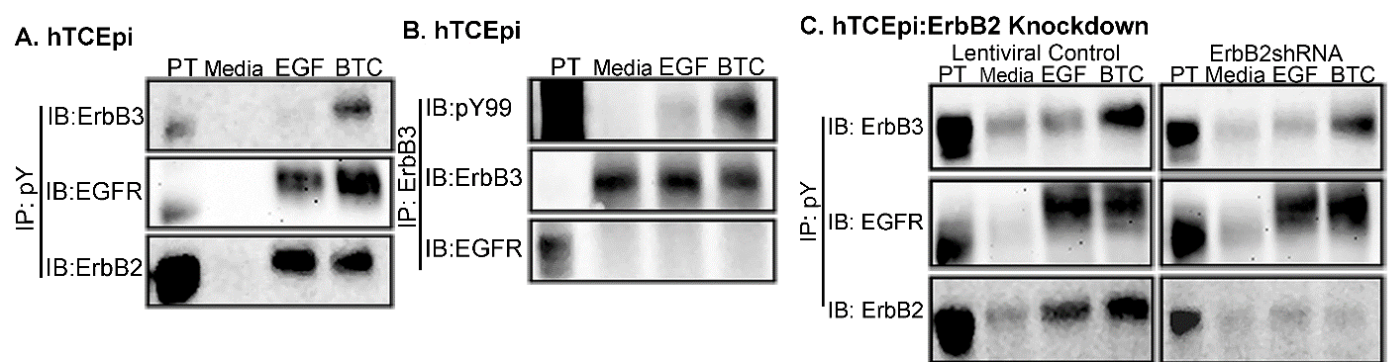

D. hTCEpi: pY:IP (Quant.)

E. hTCEpi: ErbB3:IP (Quant.) F. hTCEpi:ErbB2 Knockdown (Quantification)
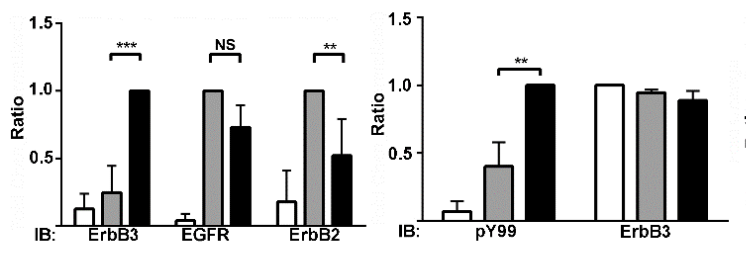

$\square$ Media $\square$ EGF $\square$ BTC

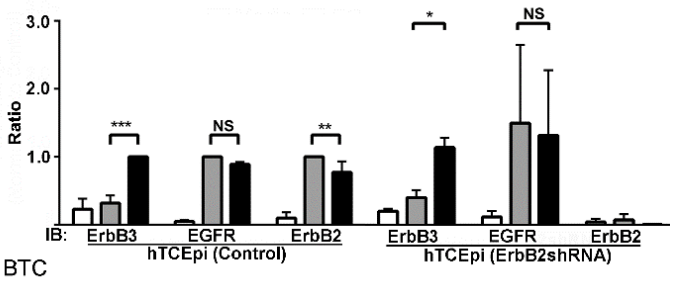

Figure 8. BTC induces ErbB3 phosphorylation in hTCEpi cells without ErbB2 interaction. A-C) hTCEpi were treated with serum free media alone, $1.6 \mathrm{nM}$ EGF, or $1.6 \mathrm{nM}$ BTC for $15 \mathrm{~min}$ as indicated. Cell lysates were prepared under denaturing conditions and the indicated proteins were immunoprecipitated using A) antiphosphotyrosine (Peterson JL), or B) anti-ErbB3 antibodies. The pass-through (PT) and immunoprecipitates were resolved by 7.5\% SDS-PAGE, and immunoblotted with the indicated antibodies. Shown are representative blots from an experiment performed at least three times. C) Transduced ErbB2-shRNA and shRNA control (materials and methods) hTCEpi cells were treated the same as A-B. Shown are representative blots from three replicates. D-F) Immunoblots from A-C were quantified using NIH Image J. Data are presented as the average ratio ( \pm S.D.) of each treatment to the most abundant protein. Blots were analyzed with a two-way ANOVA, Holm-Sidak's multiple comparisons test. ${ }^{*}=\mathrm{p}<0.05,{ }^{* *}=\mathrm{p}<0.01,{ }^{* * *}=\mathrm{p}<0.001 \mathrm{NS}=$ not significant (Rush JS). 
A. MDA-MB-468

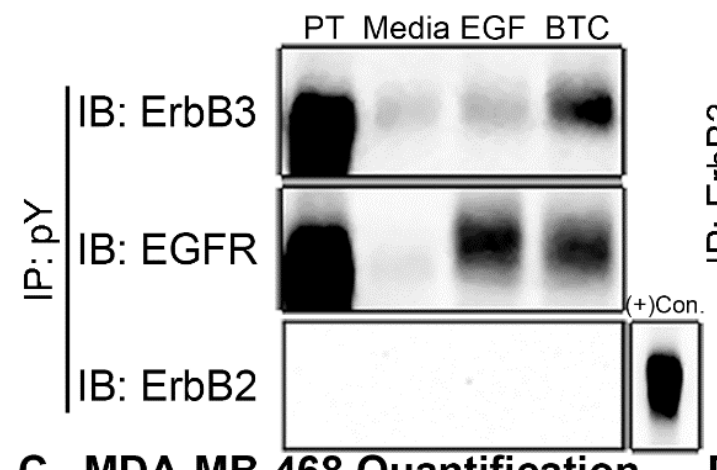

C. MDA-MB-468 Quantification

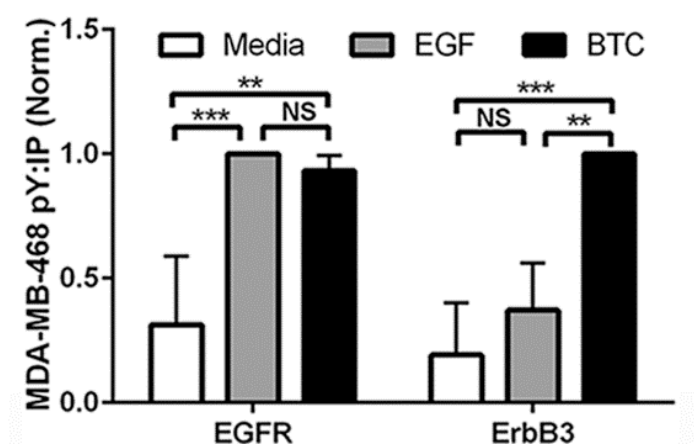

B. MDA-MB-468

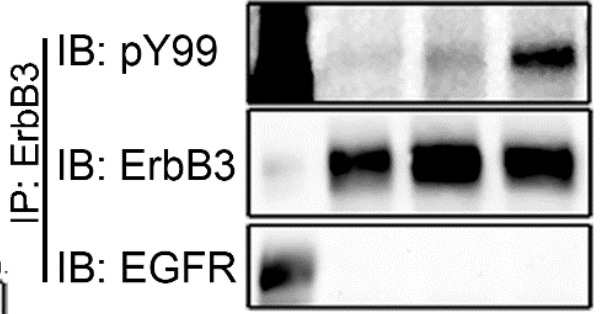

D. MDA-MB-468 Quantification

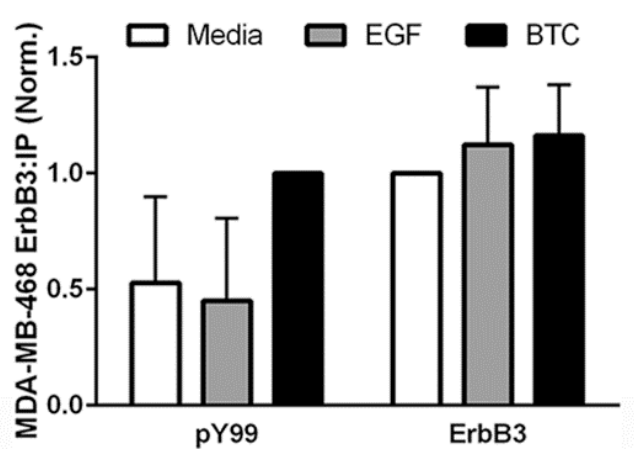

Figure 9. BTC induces ErbB3 phosphorylation in MDA-MB-468. A-B) MDA-MB-468 were treated with serum free media alone, 1.6 nM EGF, or $1.6 \mathrm{nM}$ BTC for $15 \mathrm{~min}$. Cell lysates were prepared and proteins immunoprecipitated using A) anti-phosphotyrosine or B) anti-ErbB3 antibodies. The pass-through (PT) and immunoprecipitates were resolved by $7.5 \%$ SDS-PAGE, and immunoblotted with the indicated antibodies. Shown are representative blots from an experiment performed at least three times. C-D) Blots were analyzed with a two-way ANOVA, Holm-Sidak's multiple comparisons test. Normalized experiments are presented as ratios compared to the strongest band for each blot, ${ }^{*}=\mathrm{p}<0.05,{ }^{* *}=\mathrm{p}<0.01,{ }^{* * *}=\mathrm{p}<0.001 \mathrm{NS}=$ not significant (Rush JS).

BTC promotes ErbB3 phosphorylation and EGFR:ErbB heterodimers

These biochemical data provide evidence that BTC causes ErbB3 phosphorylation, but do not demonstrate a direct interaction. Another possibility is ErbB3 phosphorylation is mediated by a non-receptor kinase that is activated by the liganded EGFR. To determine if BTC caused an increase in EGFR:ErbB3 heterodimers, we performed proximity ligation assays (PLA) (Fig 10). PLA is an antibody based detection/amplification system that will reveal protein:protein interactions when 
they are within $40 \mathrm{~nm}$. hTCEpi cells were treated with media alone, or media supplemented with EGF or BTC, fixed and subjected to the PLA protocol (see Experimental Procedures). When cells were screened for the presence of EGFR:ErbB3 heterodimers, EGF produced a 1.1 fold increase in heterodimers, and BTC produced a 2.6-fold increase (Fig 10B). Together, the receptor phosphorylation data and the PLA support the notion that EGF treated cells have less EGFR:ErbB3 heterodimer interactions when compared to those treated with BTC.

Finally, we wanted to determine if the EGFR:ErbB3 heterodimers were responsible for the increase in cell mobility that was seen with BTC treatment. We monitored ligand-dependent cell migration using a Transwell migration assay in the absence and presence of the ErbB3 antagonist antibody, MM-121 (seribantumab) [111] (Fig 11A). MM-121 treated cells migrate similarly with media alone, serum or EGF. In contrast, in the presence of MM-121, BTC treated cells no longer migrated more than EGF treated cells.

To determine the contribution of ErbB family members on BTC-mediated migration, we knocked down EGFR, ErbB2, and ErbB3 (Fig. 11B) individually. Transfection of hTCEpi cells with these siRNA attenuated expression of EGFR, ErbB2 and ErbB3 by 49\%, 78\% and 91\% respectively. The decreased levels of ErbB3 eliminated the significant BTC mediated migration advantage when compared to EGF (Fig. 11C). The loss of any of the three ErbB RTKs decreases the efficacy advantage of BTC treatments over EGF (Fig. 11C). These data are consistent with all ErbB family members contributing to BTC-mediated signaling. 
A. PLA: EGFR:ErbB3 Heterodimers
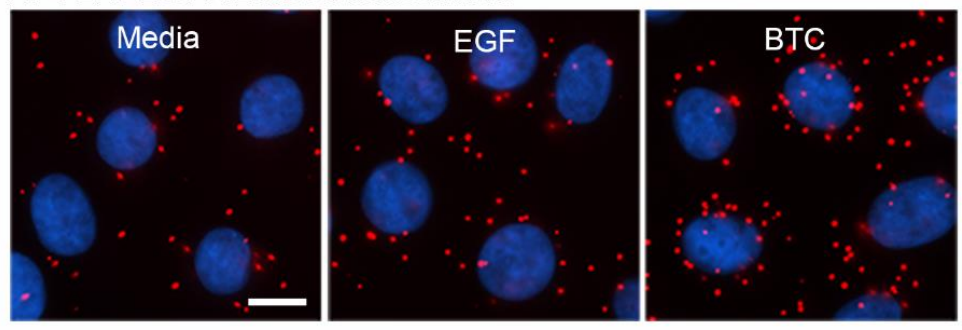

B. PLA: EGFR:ErbB3 (Total)

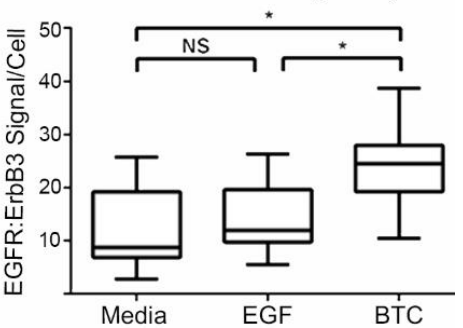

Figure 10. BTC induces EGFR:ErbB3 heterodimers in hTCEpi cells. EGFR:EGFR or EGFR:ErbB3 dimerization was visualized by proximity ligation assay (PLA). After serum starving cells for $2 \mathrm{hrs}$, hTCEpi cells were treated with serum free media alone or with $16 \mathrm{nM}$ EGF or BTC for $15 \mathrm{~min}$ at $37^{\circ} \mathrm{C}$. After treatment, cells were fixed and probed using the proximity ligation assay (PLA) as described in Material and Methods. Representative micrographs of cells probed for A) EGFR:ErbB3 heterodimers. Data from three independent experiments were quantified (50-100 cells/experiment) and are presented as the total number of signals per cell (B) and analyzed with a one-way ANOVA, HolmSidak's multiple comparisons test. Normalized experiments are presented as the number of signals compared to untreated (C), and quantification were analyzed with an unpaired student's t-test. * $=$ p $<0.05$ (Rush JS). 
A. ErbB3 inhibitor migration

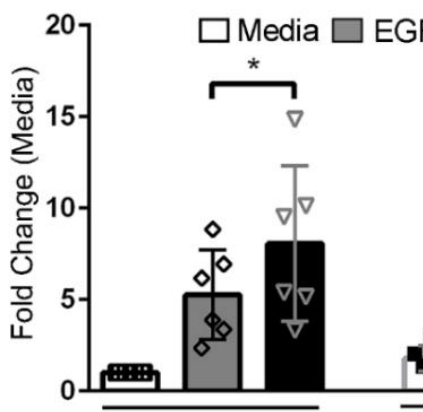

(-) MM-121

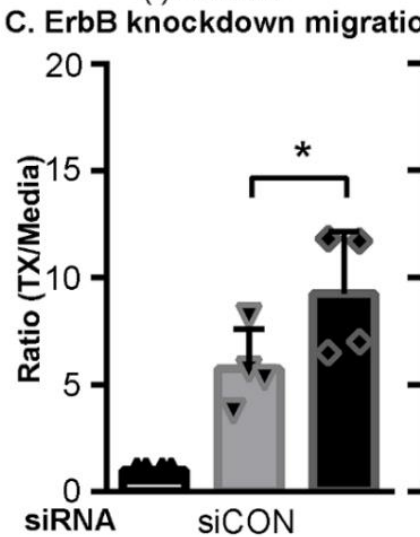

(+) MM-121
B. ErbB knockdown migration

BTC
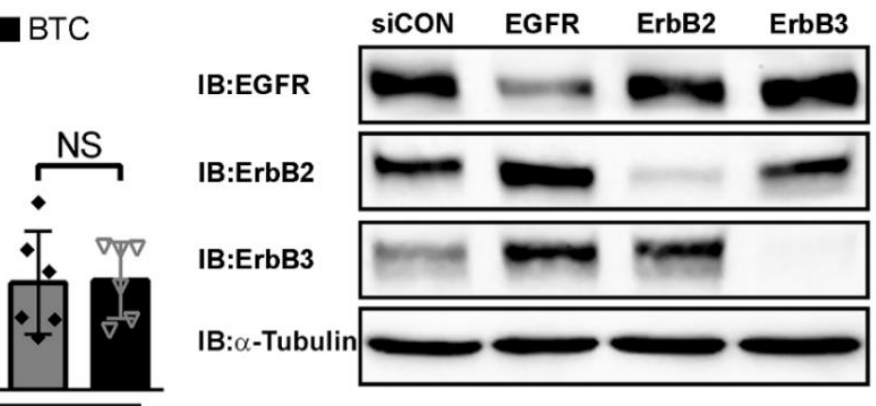
ion
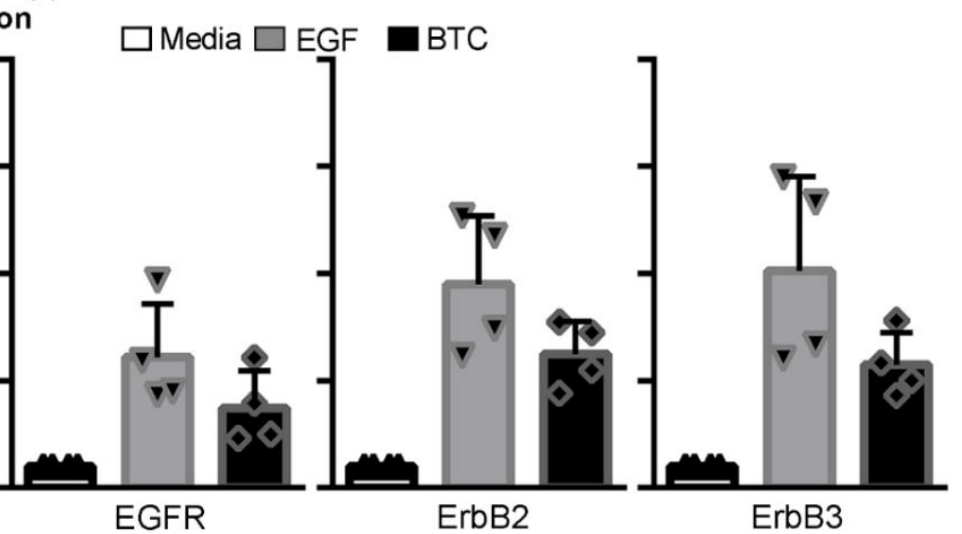

Figure 11. ErbB3 antagonist MM-121 and knockdown inhibit BTC-mediated migration to a greater extent than EGF-mediated migration. A) hTCEpi cells were plated on the upper chamber of transwells $(0.8 \mathrm{~nm}$ pore $)$ and pre-treated without or with $170 \mu \mathrm{g} / \mathrm{ml}$ MM-121 for 2 hours. The media was replaced with 1) serum free media alone, 2) EGF (1.6 nM) or 3) BTC (1.6 nM) in the absence or presence of MM-121. Cells were incubated for 16 hours and migration to the lower chamber was measured by counting the number of migrated cells on the underside of the membrane. Shown are the results of 6 independent experiments for each condition. B) hTCEpi cells were transfected with either control siRNA (siCON) or siRNA specific for EGFR, ErbB2 or ErB3 as described in Materials and Methods. After recovery (72h), B) immunoblots from cell lysates were prepared from hTCEpi samples, and equal amounts of total protein loaded. Samples were resolved by SDS-PAGE and immunoblotted with the indicated antibody. Immunoblots shown are representative from experiments performed at least 6 times. C) transwells were loaded with transfected cells as described in Materials and Methods. Migrated cells were quantified and each experiment normalized to media treated cells independently. Each y-axis indicates a different transfected hTCEpi cell-line. The results are plotted as mean \pm S.D. Data were analyzed with a two-way ANOVA with Holm-Sidak's post-hoc analysis, ${ }^{*}=\mathrm{p}<0.05, \mathrm{NS}=$ not significant (Rush JS). 


\section{Discussion}

In this manuscript, we demonstrate that EGFR-related growth factors differ in their ability to induce phosphorylation, direct specific receptor dimerization and effect cell physiology. Multiple labs have reported that BTC is more efficacious than EGF $[19,90,111,125]$. We show that in line with ligand efficacy, BTC enhances cell migration more than EGF (Fig 4 and 11), which is a fundamental component of corneal wound healing (Fig 4 and 11). Furthermore, this effect is not due to enhanced BTC binding to or phosphorylation of the EGFR (Fig 5 - 7), as these responses are reduced with BTC treatment. Rather, BTC binding to the EGFR biases the receptor to heterodimerize with ErbB3, resulting in ErbB3 phosphorylation (Fig 5-10). Importantly, BTC-mediated ErbB3 phosphorylation is independent of ErbB2. These heterodimers are more efficacious mediators of cell migration, as ErbB3 antagonists and knockdown inhibits BTC-mediated migration to a greater extent than EGFmediated migration (Fig 10).

We propose a model in which EGF and BTC both bind the EGFR, but differentially bias the dimerization partner of the ligand-bound receptor. This ligandbiased signaling is known among G-protein coupled receptors [126-128]. In the cell, monomeric ErbB RTKs and their ligands are in a biochemical equilibrium. The binding of ligand shifts the equilibrium of the receptors from a monomeric to a dimeric form. Our data here support a model in which the ligand:EGFR directs whether the dimers are homodimers or heterodimers. There is an additional layer of complexity to this model when applying it to other cell lines that express the ErbB RTKs at different levels. 
Reports in the literature have been inconsistent regarding how BTC induces ErbB3 phosphorylation [118, 129-132]. We postulate that the variability in the absolute and relative amounts of EGFR and ErbB3 are a potential source for these discrepancies. Since BTC drives the formation of EGFR:ErbB3 heterodimers, if EGFRs are in vast excess, once the maximum number of heterodimers are formed, the remaining liganded EGFRs are able to form homodimers or ErbB2 heterodimers. Our data support this hypothesis, as the loss of EGFR and ErbB2 also decreased the significant advantage BTC treatment had on migration (Fig 11). hTCEpi cells have sufficient levels of EGFR and ErbB3 that produce functional EGFR:ErbB3 heterodimers, as evident by the decreased cell migration in response to ErbB3 antagonist and ErbB3 knockdown. Cells that do not express ErbB3 may not show differences in responses to EGF and BTC migration.

Several previous studies support this model. First, Liu et al. report that a single ligand is sufficient to activate EGFR dimers [61]. While this is well accepted for ErbB RTKs that heterodimerize with the ligandless ErbB2, it is important to note that it can extend to the other family members that undergo conformational changes to dimerize. Second, our findings that receptors preferentially form dimer partners is supported by the work of MacDonald-Oberman et al. [120,133]. Our endogenous receptor model proposes that these preferences can be shifted by the activating ligand. As indicated from our PLA experiments, BTC preferentially drives the formation of EGFR:ErbB3.

It was fortunate that hTCEpi and MDA-MB-468 cells do not express ErbB4, another target for BTC binding. With the addition of ErbB4, the model would have to 
take into consideration the binding affinities for EGFR versus ErbB4. Although ErbB2 does not bind BTC, its contribution cannot be overlooked. It is likely that ErbB2 is also competing for binding to the liganded EGFRs. ErbB3 phosphorylation was unaffected by the loss of ErbB2, further supporting EGFR as the sole ligand binding receptor in our system. The incomplete inhibition of ErbB3 initiated migration in response to MM-121 may be due to compensatory ErbB2 effects. The knockdown of each ErbB RTK had an increase in protein levels of the other ErbB RTKs when compared to control lysates (data not shown), especially with EGFR knockdown (Fig. 11C). Other groups show that compensatory protein effects following knockdown of similar proteins are possible and support this phenomenon [134-136]. This effect was also supported in the receptor knockout cell lines where the loss of EGFR, ErbB2 and ErbB3 decreased the migration advantage BTC has over EGF. While ErbB2 is not necessary to activate ErbB3 with BTC, it contributes to BTC-mediated migration, like ErbB3 (Fig 11B). More rigorous mathematical modeling and experimentation are required to account for the complexities of the entire ErbB RTK family.

While it has been previously appreciated that ligands can direct dimer formation, it was largely attributed to differences between which receptor and the ligand bound [120]; our model proposes that two different ligands are binding the same receptor, but forming different heterodimer populations. How would ligand binding direct the dimerization partner? One possibility is that human EGF and BTC have limited sequence similarity ( $\sim 36 \%)$ as well as low predicted three-dimensional structural homology as measured by solvent accessibility surfaces [108]. Alternatively, the size of the ligand may affect receptor conformation. The processed 
form of BTC is $9 \mathrm{kDa}$ and $\mathrm{EGF}$ is $6.6 \mathrm{kDa}$ [46]. A stretch of $\sim 50$ amino acids directly binds to the ligand-binding domain of the receptor [137]. The size and/or charge of the remaining 30 amino acids may sterically hinder BTC:EGFR homodimerization. Fundamental differences in binding are supported by our observed differences in radioligand competition binding and $\mathrm{pH}$ sensitivity for the two ligands (Fig 5). 


\section{CHAPTER III}

BTC INDUCES DIFFERENTIAL EGFR TRAFFICKING AND COMPARABLY ACTIVATES AKT AND MAPK

\section{Introduction:}

Many tissues throughout the body express EGFR. Once ligand binds the receptor, the receptor becomes activated intracellularly and is then able to activate effectors (i.e. Shc, Grb2, c-Cbl, MAPK, AKT). The activities of these EGFR activated effectors modulate receptor trafficking and ultimately, cell physiology. EGFR activation is known to alter cell survival, proliferation, differentiation and migration. These cellular changes then translate to functional changes in tissue development, wound healing, tissue maintenance and cancer biology $[138,139]$.

The clathrin-mediated endocytic pathway is the primary molecular mechanism that balances EGFR signaling and regulation [140]. Ligand bound ErbBreceptors internalize via clathrin-coated pits and initiate the activation of downstream signaling pathways. The cargo, now inside the cell, travels through the endocytic pathway by moving from clathrin-coated vesicles to early endosomes, which mature to late endosomes/multivesicular bodies and finally to the lysosome for degradation. This process typically attenuates the EGFR signaling adequately, although the complete mechanisms remain unclear due to the complexity of this 
process. Some possible EGFR regulatory mechanisms include dephosphorylating the receptor, sequestering the receptor (decreasing effector interaction), ubiquitylation, and relocation of the receptor from the plasma membrane [141].

This study examines changes in receptor trafficking and downstream effectors in response to EGFR ligands EGF and BTC. Although we found BTC significantly increases 1) ErbB3 phosphorylation, 2) EGFR:ErbB3 interactions, 3) migration rates 4) EGFR trafficking rates in corneal cells, there was no measurable change in downstream effector signaling relative to the differences when compared to EGF. We did identify that downstream signaling between EGF and BTC was similar, despite having decreased phosphorylation of the binding receptor, EGFR. This finding indicates that other effectors/pathways are involved in EGF/BTC associated physiology changes, not trafficking.

\section{Experimental Procedures}

Cell Lines- hTCEpi cells were obtained from Geron Corp. (Menlo Park, CA). Human corneal epithelial cells were immortalized by the stable transfection of human telomerase reverse transcriptase [113]. Cells were grown in growth media (Defined Keratinocyte with growth supplement; Invitrogen, Carlsbad, CA) at $37^{\circ} \mathrm{C}$ and were maintained at $5 \% \mathrm{CO}_{2}$. HeLa cells were a gift of Sandra Schmid (The Scripps Research Institute) and were maintained in Dulbecco's Minimal Essential Media (DMEM) containing 5\% fetal bovine serum (FBS), 100 units $/ \mathrm{mL}$ penicillin, 100mg/mL streptomysin, and $2 \mathrm{mM}$ glutamine. Cell lines were maintained at $37^{\circ} \mathrm{C} \mathrm{in} 5 \% \mathrm{CO}_{2}$. Percoll Gradient Fractionation-Analysis of radioligand distribution was performed as described by Kornilova et al. (10). Briefly, hTCEpi cells were incubated for $15 \mathrm{~min}$ 
with ${ }^{125}$ I-EGF or BTC $(1 \mathrm{ng} / \mathrm{ml})$ at $37^{\circ} \mathrm{C}$ in binding buffer (DMEM, $20 \mathrm{mM}$ HEPES, $0.1 \%$ bovine serum albumin ( $\mathrm{pH}$ 7.4)). Following treatment, cells were washed three times with PBS and returned to $37{ }^{\circ} \mathrm{C}$ in growth media. After another $30,45,105 \mathrm{~min}$ $(45,60,120 \mathrm{~min}$ total), cells were washed twice with TES [10 mM triethanolamine, 1 mM EDTA, 0.25M sucrose ( $\mathrm{pH} 7.2)]$ and harvested in $2 \mathrm{ml}$ of TES. Lysates were pipetted up and down 40 times and centrifuged for $10 \mathrm{~min}$ at $200 \mathrm{x} g$ in a Sorvoll JA25.5 rotor. The supernatant was transferred to a clean tube and the pellet was resuspended in $2 \mathrm{ml}$ of TES and centrifuged again. The resulting $4 \mathrm{ml}$ of postnuclear supernatant was diluted with a $90 \%$ Percoll solution in TES to $17 \%$ in $11.5 \mathrm{ml}$. Samples were centrifuged for $25 \mathrm{~min}$ at $4{ }^{\circ} \mathrm{C}$ at $50,000 \mathrm{~g}$ in a Beckman Ti65 rotor to separate early and late endocytic compartments. Samples were fractionated into 10drop fractions (30 fractions/gradient) from the bottom and measured for radioactivity in a Beckman counter. Data are plotted as the percentage of total radioactivity in each tube versus the relative migration of each fraction in the sample. Density was monitored using density marker beads (Amersham Biosciences). Western Blotting - hTCEpi cells were washed twice with PBS pH 7.4 and incubated with serum-free KSFM for 2h. Cells were treated with 1.6 nM EGF or BTC for 15, 30, 60, 120, 240 min. Treated cells were subjected to two quick washes with PBS pH 7.4, equilibrated to $4^{\circ} \mathrm{C}$ on ice. Cells were harvested in RIPA buffer $(150 \mathrm{mM} \mathrm{NaCl}, 1 \%$ Nonidet P-40, 0.5\% deoxycholate, $0.1 \%$ SDS, $50 \mathrm{mM}$ Tris, $\mathrm{pH}$ 8.0, $10 \mathrm{mM}$ sodium pyrophosphate, $100 \mathrm{mM}$ sodium fluoride) supplemented with $2 \mathrm{mM}$ Phenylmethylsulfonyl fluoride (PMSF), solubilized with end over end rotation for 10 $\min$ at $4^{\circ} \mathrm{C}$. Insoluble material was removed by centrifugation for $10 \mathrm{~min}$ at $4^{\circ} \mathrm{C}$ and 
maximum speed (15,000 g) in an Eppendorf 5424R (Hamburg, Germany). Equivalent amounts of cell lysate were resolved by SDS-PAGE and transferred to nitrocellulose. The indicated proteins were immunoblotted using the following antibodies: EGFR (SC-373746) antibodies obtained from Santa Cruz Biotechnology (Dallas, TX), site specific phosphoEGFR antibody (pY1045), total AKT (9272, phospho-AKT, Ser473 (4051), MAPK 42/44 (4695), phospho-MAPK 42/44 (9101) from Cell Signaling (Danvers, MA), $\alpha$-tubulin antibodies were from Sigma-Aldrich (St. Louis, M0). Following incubation with the appropriate HRP-conjugated secondary antibody, immunoreactive proteins were visualized with ECL and a Fotodyne Imaging system (Hartland, WI).

\section{Results}

EGFR Trafficking Accelerated with BTC Treatment

To determine whether physiological effects of ligand treatment in hTCEpi cells is related to changes in EGFR trafficking, we quantitatively examined ${ }^{125}$ I-EGF:EGFR and 125I-BTC:EGFR endosomal distribution. Cells were treated with ${ }^{125}$ I-Ligand and chased with radioligand-free media (materials and methods). Early and late endosomes were resolved using sedimentation velocity centrifugation from cell lysate using $17 \%$ Percoll gradients. Density beads were used to verify the identity of the fractions. Low density fractions ( $\mathrm{Rf} \sim 0.3,1.040 \mathrm{~g} / \mathrm{mL}$ ) correspond to early endosomes and higher-density fractions ( $\mathrm{Rf} \sim 0.9, \Delta=1.080-1.109 \mathrm{~g} / \mathrm{mL}$ ) correspond to late endosomes [142]. 
The distribution of radioactivity in cells treated with either ${ }^{125}$ I-EGF or ${ }^{125 I-}$ BTC revealed similar trafficking and distribution of both ligands. In HeLa cells less than $50 \%$ of the starting amount of 125 I-EGF radioactivity remained at 120 minutes, with minor peaks at densities corresponding to early and late endosomes (Fig. 12A). Repeating the experiment using hTCEpi cells, less than $78 \%$ of the radioactivity after 15 min. of treatment remains at $120 \mathrm{~min}$. (Fig. 12B). Then, hTCEpi cells were treated with ${ }^{125}$ I-BTC for 120 min. with only $28-32 \%$ radioactivity remaining (Fig. 12C). Our biochemical data indicate that EGF and BTC trafficking is similar, in that there is no apparent accumulation in the various compartments. However, BTC passes through the endocytic pathway at a faster rate. 
A. ${ }^{125}$-EGF Trafficking (HeLa)

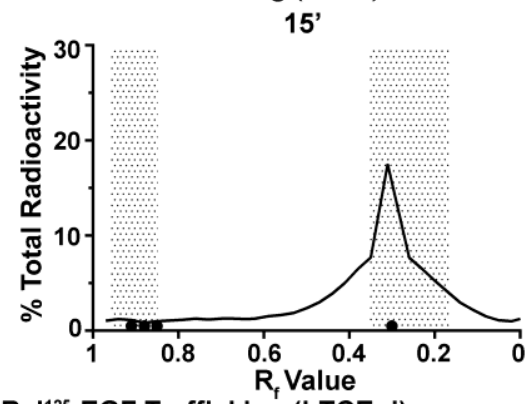

B. I $^{125}$-EGF Trafficking (hTCEpi)

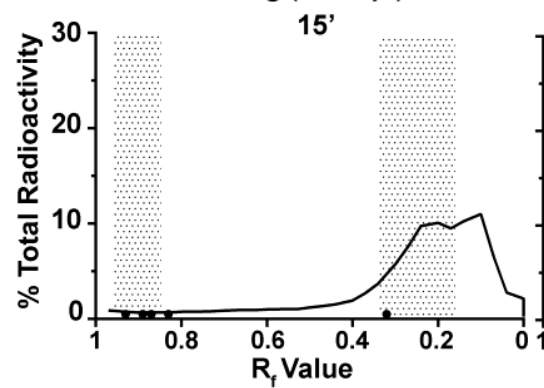

C. I'125-BTC Trafficking (hTCEpi)
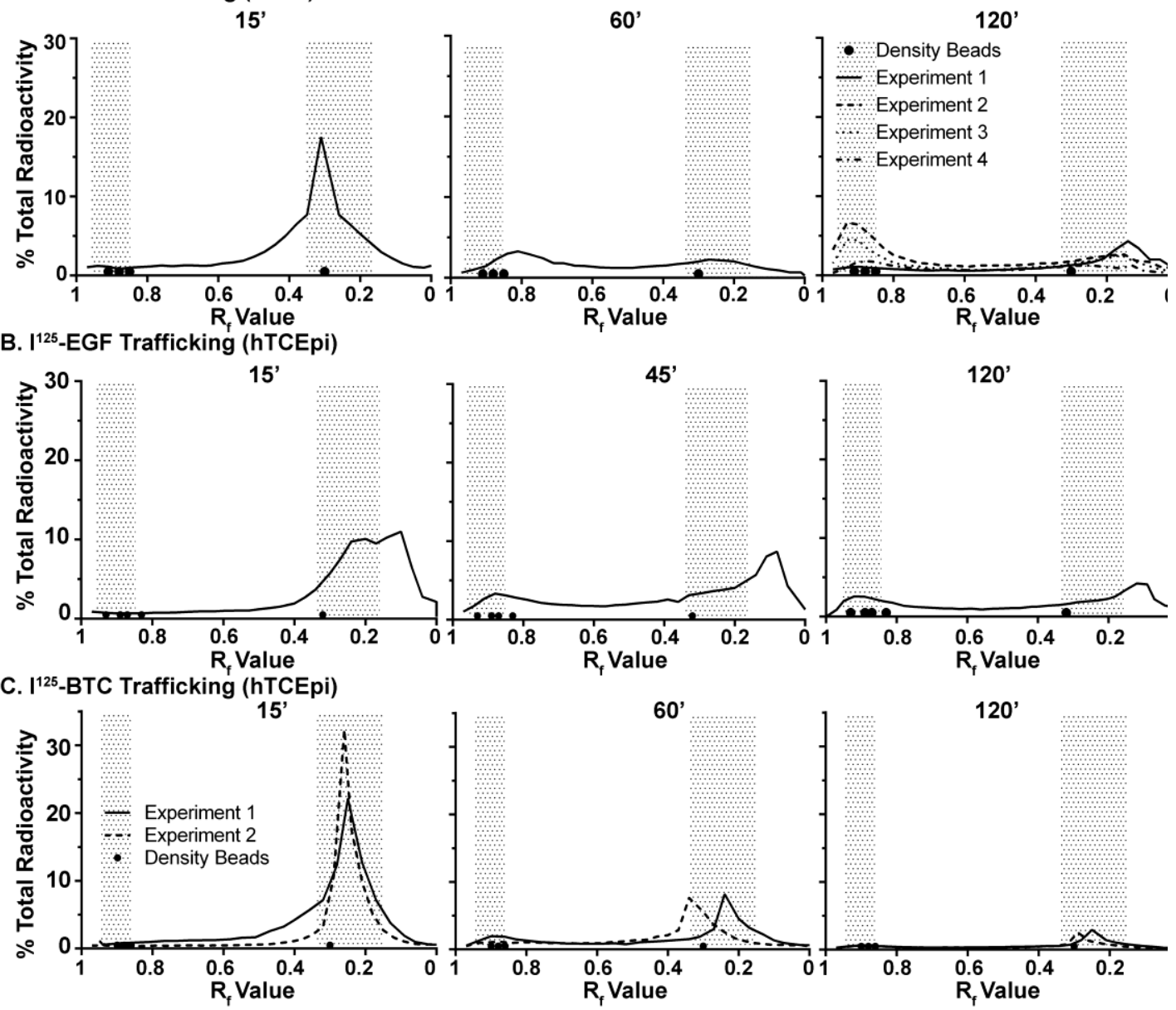

Figure 12. 125I-EGF and BTC Traffic Differentially- The endocytic trafficking of the 125I-EGF:EGFR in Hela (A) and hTCEpi (B) and 125I-BTC:EGFR complex in hTCEpi cells (C) was assessed by pulse-labeling cells with 125I-Ligand. Following a 7 min. ligand treatment followed by radioligand-free media, post-nuclear supernatant was prepared at 15,45 or 60 , and $120 \mathrm{~min}$. Data were plotted as the relative distribution of ${ }^{125}$ I in each fraction and were normalized to the total radioactivity. Circles along the $\mathrm{x}$-axis indicate the distribution of density beads (from lowest to highest Rf $\sim 0.30=1.040 \mathrm{~g} / \mathrm{mL}$, $0.85=1.055 \mathrm{~g} / \mathrm{mL}, 0.88=1.069 \mathrm{~g} / \mathrm{mL}, 0.89=1.080$ and $0.92=1.109 \mathrm{~g} / \mathrm{mL}$ ). Early endosomes migrate at 1.035 $-1.042 \mathrm{~g} / \mathrm{mL}$. The heavier late endosomes sediment with a density of $1.048-1.060 \mathrm{~g} / \mathrm{mL}$.

\section{EGF and BTC Initiated AKT and MAPK Signaling Pathways are Indistinctive}

The endocytic pathway is well regulated, and activation and downregulation

of receptors is balanced to control signaling pathways and maintain normal cell 
biology. Ligand activation of EGFR initiates signaling cascades involving multiple proteins and pathways. The physiological consequences of the activation of the various pathways are dependent on how, when and where proteins are activated or deactivated (downregulated), and potentially, which ligand initially binds to the receptor. To test that the physiological changes associated with BTC activation are due to differences in the two main proliferation/migration signaling pathways, ligand time course with both ligands was used to assess phosphorylation levels of AKT (Ser473) and MAPK.

Serum starved hTCEpi cells were treated with or without 1.6 nM EGF or BTC for 0-240 min., and total and phosphorylated EGFR, AKT (Ser473) and MAPK $(42,44)$ was measured by immunoblot analysis (Fig. 13A-C). Densitometric analysis using ImageJ to quantify the difference in total phosphorylation relative to total protein (Fig. 13B, C). We observed unexpected indistinguishable activation of proliferation/migration signaling pathways. BTC induces comparable levels of activation of both AKT and MAPK compared to EGF, even though BTC induces less EGFR phosphorylation and increased ErbB3 phosphorylation. 


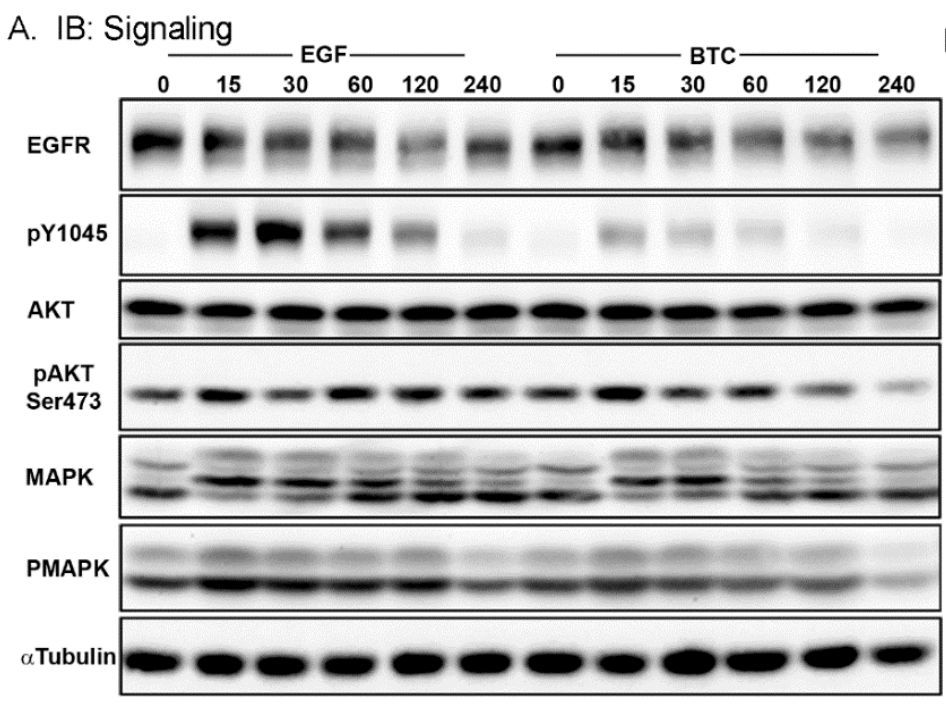

B. Quantification

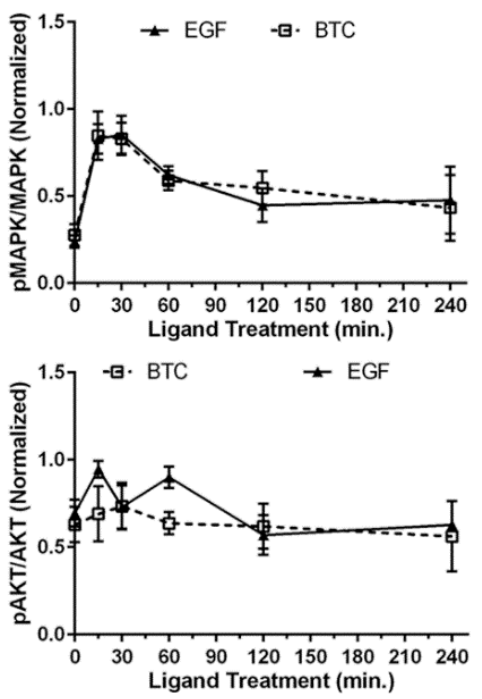

Figure 13. EGF and BTC have comparable effector signaling-Cells were treated with 1.6 nM EGF or $1.6 \mathrm{nM}$ BTC for the indicated times. Cell lysates were prepared and immunobloted with the indicated EGFR phosphotyrosine 1045, total EGFR, phosphoAKT(Ser473), total AKT, phospho-MAPK (42/44), total MAPK (42/44) or $\alpha$-tubulin. A) hTCEpi cell representative blots from three xperiments. B) Western blots quantified using ImageJ software. Phospho-blots were normalized to the corresponding total.

\section{Discussion}

We have demonstrated previously that BTC induces migration more efficiently than EGF in immortalized human corneal epithelial cells [19]. In a previous study (Chapter II), we demonstrated that BTC induces increased signaling of ErbB3 and heterodimers of EGFR and ErbB3. From the data, we developed the hypothesis that increased effector signaling from ErbB3 or changes in trafficking would precede BTC induced enhanced migration.

To test this hypothesis, we used hTCEpi cells and monitored EGFR endocytic trafficking ${ }^{125} \mathrm{I}-\mathrm{EGF}$ and BTC. If the rate of EGFR trafficking increases, we would expect a decrease in total ${ }^{125}$ I over time; if trafficking slows, overall radioactivity levels would increase, as well as the amount of ${ }^{125}$ I at the density regions associated 
with early or late endosomes. We observed similar trafficking between HeLa and hTCEpi cells treated with ${ }^{125}$ I-EGF, with some experimental variability. However, hTCEpi cells treated with ${ }^{125}$ I-BTC showed $<3$ fold difference in total radioactivity after remaining at $120 \mathrm{~min}$, when compared to EGF. Visually comparing Hela (Fig. 12A) and hTCEpi cells (Fig. 12C) at $60 \mathrm{~min}$. , you can see a well-defined peak in hTCEpi cells in the region associated with early endosome densities. However, the Hela cells at this same time point show small peaks in early and late endosomal regions and an overall accumulation of ${ }^{125}$ I-EGF compared with ${ }^{125 I-B T C . ~ T h i s ~ i n d i c a t e s ~ t h a t ~ B T C ~ i s ~}$ processing through the late endosome at a faster rate. We showed previously that EGF dissociates from EGFR at a higher pH than BTC, allowing BTC to stay bound longer to EGFR throughout the endocytic pathway. These data support a model where BTC can stay bound longer to the receptor, but does not apparently change the kinetics of ligand:receptor trafficking based on Percoll gradients. Instead, when the trafficking data and receptor degradation data are combined, the complex seems to be trafficking through the endocytic pathway at a slightly faster rate, as supported by other publications $[66,143]$.

MAPK and AKT are well known pathways associated with regulating the migration and proliferation of cells [144-146]. ErbB3 has seven known direct binding sites for PI3-kinase, an upstream activator of the AKT pathway. We hypothesized that BTC induced phosphorylation of ErbB3 would cause an increase of AKT activity when compared to EGF treatment. We used immunoblotting to examine phosphorylation patterns and unexpectedly, we saw comparable, at times indistinguishable signaling patterns from both ligands. This data suggests that even 
though BTC has decreased activation of EGFR, downstream signaling is comparable, from heterodimer-initiated pathways.

EGFR overexpression, hyperactivation and mutations in several types of cancers is associated with poor patient prognosis [147]. This connection to disease is harmonious with the receptor's ability to induce cell proliferation, migration, differentiation and viability. Hyperactivation of EGFR related to disease makes EGFR a logical pharmacological target for cancer therapies including humanized monoclonal antibodies (mAb) and small molecule kinase inhibitors. mABs block the activation of the receptor by ligand binding, while TKIs bind the kinase domain and prevent receptor signaling. While both types of EGFR inhibitors prove to be effective at suppressing tumor growth in the short term, most patients acquire resistance. In addition, patients using EGFR inhibitor therapy experience colitis, diarrhea, dermatitis, and persistent corneal erosions. A deeper knowledge of EGFR:ErbB trafficking, effector activation is needed to make drugs that are more effective with less side effects and resistance. It has been suggested that compensatory networks (heterodimers, increased protein expression, etc.) could be one reason resistance occurs at such a high rate.

A deeper understanding and broader knowledge of EGFR trafficking and signaling is needed to expand and improve targeted therapies. This study provides evidence that two EGFR ligands that bind the same receptor can traffic differentially and signal comparably even with diverse activation of the binding receptor. 


\section{CHAPTER IV}

\section{SUMMARY AND CONCLUSIONS}

The EGFR and the ErbB-family of receptors form a complex signaling network with twenty-four possible ErbB-receptor combinations directed by eleven different ligands. Since the initial discovery of EGF ligand in the 60 s by the Cohen group, researchers have elucidated some of the basic mechanics of receptor and ligand binding possibilities, but how ligand choice and dimer pairing effects signaling networks and cell physiology remains unclear. Examining the migration rate changes of two ligands (EGF and BTC) bound to one ErbB-receptor (EGFR) preempted this study of ligand-initiated mechanisms. Using hTCEpi cells, void of ErbB4, and limiting our study to two ligands that only bind EGFR, we were able to deduce a few basic mechanisms that are involved in BTC enhanced migration.

We discovered that even though BTC has decreased activation of EGFR at equal concentrations to EGF, it is able to activate more EGFR:ErbB3 heterodimers and consequentially phosphorylate more ErbB3. The phosphorylation of ErbB3 by BTC could be the reason both EGF and BTC comparably activate the MAPK/AKT pathways, even without comparable phosphorylation of EGFR. Both EGFR and ErbB3 have receptor specific binding to effectors important for cell proliferation and migration. ErbB3 has seven known direct binding sites for phosphatidylinositol-3-kinase (PI3K), where EGFR has no direct PI3K sites, but can activate PI3K through two Grb2 binding 
sites. Even though Grb2 can also activate PI3K, ErbB3 has more binding potential with PI3K, a known activator of mTOR and AKT pathways. Both mTOR and AKT are important components of the proliferation and migration mechanisms in cell biology.

ErbB2:ErbB3 dimer pairings have been associated with proliferation and migration, some studies showing one without the other inhibits migration. In our study, we saw that ErbB3 is activated by BTC, even without the availability of ErbB2. However, the loss of any of the ErbB-family of receptors in the hTCEpi cells limited the enhanced migration advantage BTC has compared to EGF. This indicates that while BTC has the potential to activate unique signaling pathways associated with ErbB3 phosphorylation, without the ability to bind EGFR or ErbB2, physiological advantages are limited or void.

Because EGFR is spatially and temporally regulated, cell physiology changes are partially the result of how, where and how quickly EGFR traffics. When we compared ${ }^{125}$ I-EGF and ${ }^{125} \mathrm{I}-\mathrm{BTC}$, we found that the receptor did not appear to accumulate in distinct endocytic compartments. However, when total radioactivity changes between $15 \mathrm{~min}$. and $120 \mathrm{~min}$., BTC progressed through the endocytic pathway at a noticeably faster rate. We also saw that BTC remained bound to EGFR at a lower $\mathrm{pH}$ level than EGF, allowing the receptor to continue to signal throughout the endocytic pathway. When the receptor complex remains activated throughout endocytosis, the opportunity to interact with more downstream effectors increases, ultimately effecting cell physiology like migration and proliferation. 
While this study only reveals a small part of the mechanisms involved in ligand-initiated cell migration and wound healing by EGFR and two of its ligands, it is an important step in simplifying the complex story of receptor regulation by ligand specification.

\section{Limitations of This Work}

hTCEpi cells endogenously express three of the four ErbB-receptors. Their ErbB-receptor's ability to heterodimerize with each other and activate by binding to nine different ligands, creates an overlapping spider web of activation, deactivation, downregulation and recycling. This network of differential signaling limits how many comparisons you can perform at one time and requires careful experimental design to limit confusion and focus analysis. Direct comparison between a limited number of receptors and ligands that only bind one receptor is the best way is to compare ligands. However, pharmacological inhibition can have off target effects and knockdown can lead to compensatory production or increased activity of relative proteins. Choosing cell lines that endogenously express a physiologically relevant number of receptors would be ideal, as that would ensure studying a biological process. However, not every cell line has known receptors or receptor densities, and analysis to deduced receptor concentrations in a variety of cells would be insurmountable.

Another limitation to this study is the lack of quality human specific antibodies to analyze phosphorylation levels of many of the effectors associated with proliferation and migration in the EGFR signaling pathway. PI3K is a critical regulator of the migration pathway, but human specific antibodies for phosphorylated PI3K 
proteins are currently not available. Often, a ${ }^{32} \mathrm{P}-\mathrm{ATP}$ assay is used to assess PI3K activity following ligand activation, but this is a multi-step process that requires the right equipment and expertise to analyze the assay effectively.

\section{Strengths of This Work}

A major strength of this work is the study focuses on the basic biology related to a physiologically important process, cell migration. The basic mechanism assay (receptor phosphorylation/PLA) results reveal molecular interactions that are quantifiable and translatable to other cells lines besides cornea epithelial cells.

The in vitro cultivation of cell lines derived from the corneal epithelium has become a powerful technique for research. It is also important to note that using a substitute animal model used to assay drugs and other compounds is ethically responsible. While it is still required to test new drugs and compounds in vivo, performing research in an in vitro model can decrease the number and duration of animals used in a study.

\section{Future Directions}

The study of EGFR activation, regulation and signaling continues to be important for wound healing, cancer screening, regulation of cancer drug side effects and EGFR targeted therapies. Even though a thorough understanding of individual receptor mechanics is available, the impact of ligands and dimer pairings is still unclear. Can a ligand be clinically useful to improve the quality of wound healing while also decreasing the time to heal? A comprehensive study looking at ligand binding, receptor dimers and effectors collectively would clarify the contributions of each of the EGF-like ligands. Looking at receptors systematically in cell lines that 
endogenously contain certain ErbB rectors can eliminate some of the complexities without interrupting the normal cell function. A large-scale study of ErbB receptors in a variety of cells from multiple tissue types, normal and cancerous, would afford researchers the opportunity to choose cell lines with specific receptor qualities and document physiology changes after ligand activation. Multiplex assays have become more mainstream, but the expense of the equipment and the price of consumables associated with the assay have limited the scope of its contribution to ErbB receptor signaling. Multi-plex assays that could analyze the phosphorylation of every known effector would allow for direct comparison between ligand effects on the signaling pathways. Being able to analyze at multiple time points would be cumbersome, but necessary as effectors are activated at different times during endocytosis.

A much deeper understanding the effectors involved in BTC induced cell migration can not only be helpful to produce new treatments for corneal wounds, but also be relative to cancer therapies that target EGFR, EGFR signaling and manipulate receptor agonist/antagonist. BTC overexpression has been associated with certain cancer types, and using the data acquired from this study, you can see the possible contribution of BTC in EGFR inhibitor resistance.

The individual contributions of all of the ErbB-receptor ligands, and how dimer-pairing choice initiates downstream effectors, is critical to formulating new treatments for corneal wound healing. Just as important as quality of life improvements with rapid wound repair, is answering the question of how receptor/ligand choice can circumvent receptor knockdown and inhibition. 


\section{REFERENCES}

1. Cohen, S., Isolation of a mouse submaxillary gland protein accelerating incisor eruption and eyelid opening in the new-born animal. J Biol Chem, 1962. 237: p. 1555-62.

2. Chen, J.C., et al., Expression and Function of the Epidermal Growth Factor Receptor in Physiology and Disease. Physiological Reviews, 2016. 96(3): p. 1025-1069.

3. Sibilia, M. and E.F. Wagner, Strain-dependent epithelial defects in mice lacking the EGF receptor. Science, 1995. 269(5221): p. 234-8.

4. Hansen, L.A., et al., Genetically null mice reveal a central role for epidermal growth factor receptor in the differentiation of the hair follicle and normal hair development. Am J Pathol, 1997. 150(6): p. 1959-75.

5. Sibilia, M., et al., A strain-independent postnatal neurodegeneration in mice lacking the EGF receptor. Embo j, 1998. 17(3): p. 719-31.

6. Choi, S., Encyclopedia of signaling molecules. 2018, Springer: Cham, Switzerland:.

7. Wakeling, E.L., et al., Human EGFR, a candidate gene for the Silver-Russell syndrome, is biallelically expressed in a wide range of fetal tissues. Eur J Hum Genet, 1998. 6(2): p. 158-64.

8. Estrada C, V.A., Epidermal Growth Factor Receptor in the Adult Brain, in Cell Cycle in the Central Nervous System. 2006. p. 265-277.

9. Burton, M.J., Corneal blindness: Prevention, treatment and rehabilitation. Community Eye Health, 2009. 22(71): p. 33-35.

10. Sen, E., et al., Seasonal distribution of ocular conditions treated at the emergency room: a 1-year prospective study. Arq Bras Oftalmol, 2018. 81(2): p. 116-119.

11. Yoshioka, R., et al., Corneal epithelial wound healing impaired in keratinocyte-specific HB-EGF-deficient mice in vivo and in vitro. Invest Ophthalmol Vis Sci, 2010. 51(11): p. 5630-9.

12. Lu, L., P.S. Reinach, and W.W. Kao, Corneal epithelial wound healing. Exp Biol Med (Maywood), 2001. 226(7): p. 653-64.

13. Dupps, W.J., Jr. and S.E. Wilson, Biomechanics and wound healing in the cornea. Exp Eye Res, 2006. 83(4): p. 709-20.

14. Maurer, J.K., et al., Confocal microscopic characterization of initial corneal changes of surfactant-induced eye irritation in the rabbit. Toxicol Appl Pharmacol, 1997. 143(2): p. 291-300.

15. Furrer, P., et al., Application of in vivo confocal microscopy to the objective evaluation of ocular irritation induced by surfactants. Int J Pharm, 2000. 207(1-2): p. 89-98.

16. Pitts, D.G., J.P. Bergmanson, and L.W. Chu, Ultrastructural analysis of corneal exposure to UV radiation. Acta Ophthalmol (Copenh), 1987. 65(3): p. 263-73.

17. Pitts, D.G., A.P. Cullen, and P.D. Hacker, Ocular effects of ultraviolet radiation from 295 to $365 \mathrm{~nm}$. Invest Ophthalmol Vis Sci, 1977. 16(10): p. 932-9.

18. Schlessinger, J., Allosteric regulation of the epidermal growth factor receptor kinase. J Cell Biol, 1986. 103(6 Pt 1): p. 2067-72. 
19. Peterson, J.L., et al., The role of endogenous epidermal growth factor receptor ligands in mediating corneal epithelial homeostasis. Invest Ophthalmol Vis Sci, 2014. 55(5): p. 2870-80.

20. Wieduwilt, M.J. and M.M. Moasser, The epidermal growth factor receptor family: biology driving targeted therapeutics. Cell Mol Life Sci, 2008. 65(10): p. 1566-84.

21. Chen, J.C., et al., Expression and Function of the Epidermal Growth Factor Receptor in Physiology and Disease. Physiol Rev, 2016. 6(3): p. 1025-69.

22. Ullrich, A., et al., Human epidermal growth factor receptor CDNA sequence and aberrant expression of the amplified gene in A431 epidermoid carcinoma cells. Nature, 1984. 309(5967): p. 418-25.

23. Lax, I., et al., Localization of a major receptor-binding domain for epidermal growth factor by affinity labeling. Mol Cell Biol, 1988. 8(4): p. 1831-4.

24. Bajaj, M., et al., On the tertiary structure of the extracellular domains of the epidermal growth factor and insulin receptors. Biochim Biophys Acta, 1987. 916(2): p. 220-6.

25. Kumagai, T., et al., Role of extracellular subdomains of $p 185<$ sup $>c-n e u</$ sup $>$ and the epidermal growth factor receptor in ligand-independent association and transactivation. Proceedings of the National Academy of Sciences, 2003. 100(16): p. 9220-9225.

26. Ogiso, H., et al., Crystal structure of the complex of human epidermal growth factor and receptor extracellular domains. Cell, 2002. 110(6): p. 775-87.

27. Ferguson, K.M., et al., EGF activates its receptor by removing interactions that autoinhibit ectodomain dimerization. Mol Cell, 2003. 11(2): p. 507-17.

28. Tao, R.H. and I.N. Maruyama, All EGF(ErbB) receptors have preformed homo- and heterodimeric structures in living cells. J Cell Sci, 2008. 121(Pt 19): p. 3207-17.

29. $\mathrm{Yu}, \mathrm{X}$., et al., Ligand-independent dimer formation of epidermal growth factor receptor (EGFR) is a step separable from ligand-induced EGFR signaling. Mol Biol Cell, 2002. 13(7): p. 2547-57.

30. Cho, H.S., et al., Structure of the extracellular region of HER2 alone and in complex with the Herceptin Fab. Nature, 2003. 421(6924): p. 756-60.

31. Garrett, T.P., et al., Crystal structure of a truncated epidermal growth factor receptor extracellular domain bound to transforming growth factor alpha. Cell, 2002. 110(6): p. 763-73.

32. Mendrola, J.M., et al., The single transmembrane domains of ErbB receptors selfassociate in cell membranes. J Biol Chem, 2002. 277(7): p. 4704-12.

33. Gerber, D., N. Sal-Man, and Y. Shai, Two motifs within a transmembrane domain, one for homodimerization and the other for heterodimerization. J Biol Chem, 2004. 279(20): p. 21177-82.

34. Berger, M.B., J.M. Mendrola, and M.A. Lemmon, ErbB3/HER3 does not homodimerize upon neuregulin binding at the cell surface. FEBS Lett, 2004. 569(1-3): p. 332-6.

35. Gulliford, T., X. Ouyang, and R.J. Epstein, Intensification of growth factor receptor signalling by phorbol treatment of ligand-primed cells implies a dimer-stabilizing effect of protein kinase C-dependent juxtamembrane domain phosphorylation. Cell Signal, 1999. 11(4): p. 245-52.

36. He, L. and K. Hristova, Consequences of replacing EGFR juxtamembrane domain with an unstructured sequence. Sci Rep, 2012. 2: p. 854.

37. Red Brewer, M., et al., The juxtamembrane region of the EGF receptor functions as an activation domain. Mol Cell, 2009. 34(6): p. 641-51. 
38. Thiel, K.W. and G. Carpenter, Epidermal growth factor receptor juxtamembrane region regulates allosteric tyrosine kinase activation. Proc Natl Acad Sci U S A, 2007. 104(49): p. 19238-43.

39. Stamos, J., M.X. Sliwkowski, and C. Eigenbrot, Structure of the epidermal growth factor receptor kinase domain alone and in complex with a 4-anilinoquinazoline inhibitor. J Biol Chem, 2002. 277(48): p. 46265-72.

40. Jura, N., et al., Mechanism for activation of the EGF receptor catalytic domain by the juxtamembrane segment. Cell, 2009. 137(7): p. 1293-307.

41. Zhang, X., et al., An allosteric mechanism for activation of the kinase domain of epidermal growth factor receptor. Cell, 2006. 125(6): p. 1137-49.

42. Guy, P.M., et al., Insect cell-expressed p180erbB3 possesses an impaired tyrosine kinase activity. Proc Natl Acad Sci U S A, 1994. 91(17): p. 8132-6.

43. Sierke, S.L., et al., Biochemical characterization of the protein tyrosine kinase homology domain of the ErbB3 (HER3) receptor protein. Biochem J, 1997. 322 ( Pt 3): p. 757-63.

44. Shi, F., et al., ErbB3/HER3 intracellular domain is competent to bind ATP and catalyze autophosphorylation. Proc Natl Acad Sci U S A, 2010. 107(17): p. 7692-7.

45. Schlessinger, J. and M.A. Lemmon, SH2 and PTB domains in tyrosine kinase signaling. Sci STKE, 2003. 2003(191): p. Re12.

46. Harris, R.C., E. Chung, and R.J. Coffey, EGF Receptor ligands. Exp Cell Res, 2003. 284(1): p. 2-13.

47. Schneider, M.R. and E. Wolf, The epidermal growth factor receptor ligands at a glance. J Cell Physiol, 2009. 218(3): p. 460-6.

48. Pintar, A., et al., Exon 6 of human JAG1 encodes a conserved structural unit. BMC Struct Biol, 2009. 9: p. 43.

49. Rebay, I., et al., Specific EGF repeats of Notch mediate interactions with Delta and Serrate: implications for Notch as a multifunctional receptor. Cell, 1991. 67(4): p. 687-99.

50. Taylor, S.R., M.G. Markesbery, and P.A. Harding, Heparin-binding epidermal growth factor-like growth factor (HB-EGF) and proteolytic processing by a disintegrin and metalloproteinases (ADAM): A regulator of several pathways. Seminars in Cell \& Developmental Biology, 2014. 28: p. 22-30.

51. Junier, M.-P., What role(s) for TGFa in the central nervous system? Progress in Neurobiology, 2000. 62(5): p. 443-473.

52. Luetteke, N.C., et al., Targeted inactivation of the EGF and amphiregulin genes reveals distinct roles for EGF receptor ligands in mouse mammary gland development. Development, 1999. 126(12): p. 2739-50.

53. Jones, J.T., R.W. Akita, and M.X. Sliwkowski, Binding specificities and affinities of egf domains for ErbB receptors. FEBS Lett, 1999. 447(2-3): p. 227-31.

54. Krall, J.A., E.M. Beyer, and G. MacBeath, High-and low-affinity epidermal growth factor receptor-ligand interactions activate distinct signaling pathways. PLoS One, 2011. 6(1): p. e15945.

55. Macdonald, J.L. and L.J. Pike, Heterogeneity in EGF-binding affinities arises from negative cooperativity in an aggregating system. Proc Natl Acad Sci U S A, 2008. 105(1): p. 112-7.

56. Alvarado, D., D.E. Klein, and M.A. Lemmon, Structural basis for negative cooperativity in growth factor binding to an EGF receptor. Cell, 2010. 142(4): p. 568-79.

57. Mayawala, K., D.G. Vlachos, and J.S. Edwards, Heterogeneities in EGF receptor density at the cell surface can lead to concave up scatchard plot of EGF binding. FEBS Lett, 2005. 579(14): p. 3043-7. 
58. Macdonald-Obermann, J.L. and L.J. Pike, Allosteric regulation of epidermal growth factor (EGF) receptor ligand binding by tyrosine kinase inhibitors. J Biol Chem, 2018. 293(35): p. 13401-13414.

59. Defize, L.H., et al., Signal transduction by epidermal growth factor occurs through the subclass of high affinity receptors. J Cell Biol, 1989. 109(5): p. 2495-507.

60. Ha, S.H. and J.E. Ferrell, Jr., Thresholds and ultrasensitivity from negative cooperativity. Science, 2016. 352(6288): p. 990-3.

61. Liu, P., et al., A single ligand is sufficient to activate EGFR dimers. Proceedings of the National Academy of Sciences of the United States of America, 2012. 109(27): p. 108616.

62. Yarden, Y. and J. Schlessinger, Epidermal growth factor induces rapid, reversible aggregation of the purified epidermal growth factor receptor. Biochemistry, 1987. 26(5): p. 1443-51.

63. Sweeney, C., et al., Ligand discrimination in signaling through an ErbB4 receptor homodimer. J Biol Chem, 2000. 275(26): p. 19803-7.

64. Guo, L., et al., Studies of ligand-induced site-specific phosphorylation of epidermal growth factor receptor. J Am Soc Mass Spectrom, 2003. 14(9): p. 1022-31.

65. Saito, T., et al., Differential activation of epidermal growth factor (EGF) receptor downstream signaling pathways by betacellulin and EGF. Endocrinology, 2004. 145(9): p. 4232-43.

66. Roepstorff, K., et al., Differential effects of EGFR ligands on endocytic sorting of the receptor. Traffic, 2009. 10(8): p. 1115-27.

67. Rutten, M.J., et al., Identification of an EGF/TGF-alpha receptor in primary cultures of guinea pig gastric mucous epithelial cells. Am J Physiol, 1996. 270(4 Pt 1): p. G604-12.

68. Gruenberg, J. and F.R. Maxfield, Membrane transport in the endocytic pathway. Curr Opin Cell Biol, 1995. 7(4): p. 552-63.

69. McClintock, J.L. and B.P. Ceresa, Transforming growth factor-\{alpha\} enhances corneal epithelial cell migration by promoting EGFR recycling. Invest Ophthalmol Vis Sci, 2010. 51(7): p. 3455-61.

70. Levkowitz, G., et al., Ubiquitin ligase activity and tyrosine phosphorylation underlie suppression of growth factor signaling by c-Cbl/Sli-1. Mol Cell, 1999. 4(6): p. 1029-40.

71. Shing, Y., et al., Betacellulin: a mitogen from pancreatic beta cell tumors. Science, 1993. 259(5101): p. 1604-7.

72. Dunbar, A.J. and C. Goddard, Structure-function and biological role of betacellulin. Int J Biochem Cell Biol, 2000. 32(8): p. 805-15.

73. Yamamoto, K., et al., Recombinant human betacellulin promotes the neogenesis of betacells and ameliorates glucose intolerance in mice with diabetes induced by selective alloxan perfusion. Diabetes, 2000. 49(12): p. 2021-7.

74. Li, L., et al., Promotion of beta-cell regeneration by betacellulin in ninety percentpancreatectomized rats. Endocrinology, 2001. 142(12): p. 5379-85.

75. Li, L., et al., Betacellulin improves glucose metabolism by promoting conversion of intraislet precursor cells to beta-cells in streptozotocin-treated mice. Am J Physiol Endocrinol Metab, 2003. 285(3): p. E577-83.

76. Dunbar, A.J., et al., Identification of betacellulin as a major peptide growth factor in milk: purification, characterization and molecular cloning of bovine betacellulin. Biochem J, 1999. 344 Pt 3: p. 713-21.

77. Howarth, G.S., et al., Betacellulin promotes growth of the gastrointestinal organs and effects a diuresis in normal rats. Growth Factors, 2003. 21(2): p. 79-86. 
78. Jackson, L.F., et al., Defective valvulogenesis in HB-EGF and TACE-null mice is associated with aberrant BMP signaling. The EMBO journal, 2003. 22(11): p. 2704-16.

79. Yokoyama, M., et al., Betacellulin, a member of the epidermal growth-factor family, is overexpressed in human pancreatic-cancer. International journal of oncology, 1995. 7(4): p. 825-9.

80. Srinivasan, R., et al., Expression of the c-erbB-3/HER-3 and c-erbB-4/HER-4 growth factor receptors and their ligands, neuregulin-1 alpha, neuregulin-1 beta, and betacellulin, in normal endometrium and endometrial cancer. Clin Cancer Res, 1999. 5(10): p. 2877-83.

81. Valabrega, G., F. Montemurro, and M. Aglietta, Trastuzumab: mechanism of action, resistance and future perspectives in HER2-overexpressing breast cancer. Ann Oncol, 2007. 18(6): p. 977-84.

82. Schneider, M.R., et al., Betacellulin overexpression in transgenic mice causes disproportionate growth, pulmonary hemorrhage syndrome, and complex eye pathology. Endocrinology, 2005. 146(12): p. 5237-46.

83. Daniele, S., et al., The effect of the epidermal growth factor (EGF) on the corneal epithelium in humans. Albrecht Von Graefes Arch Klin Exp Ophthalmol, 1979. 210(3): p. 159-65.

84. Pastor, J.C. and M. Calonge, Epidermal growth factor and corneal wound healing. A multicenter study. Cornea, 1992. 11(4): p. 311-4.

85. Kandarakis, A.S., C. Page, and H.E. Kaufman, The effect of epidermal growth factor on epithelial healing after penetrating keratoplasty in human eyes. Am J Ophthalmol, 1984. 98(4): p. 411-5.

86. Dellaert, M.M., et al., Influence of topical human epidermal growth factor on postkeratoplasty re-epithelialisation. Br J Ophthalmol, 1997. 81(5): p. 391-5.

87. Oh, Y.S., et al., Betacellulin-Induced Beta Cell Proliferation and Regeneration Is Mediated by Activation of ErbB-1 and ErbB-2 Receptors. PLOS ONE, 2011. 6(8): p. e23894.

88. Ishiyama, N., et al., Studies on the betacellulin receptor in pancreatic AR42J cells. Diabetologia, 1998. 41(6): p. 623-8.

89. Pinkas-Kramarski, R., et al., The oncogenic ErbB-2/ErbB-3 heterodimer is a surrogate receptor of the epidermal growth factor and betacellulin. Oncogene, 1998. 16(10): $p$. 1249-58.

90. Beerli, R.R. and N.E. Hynes, Epidermal growth factor-related peptides activate distinct subsets of ErbB receptors and differ in their biological activities. The Journal of biological chemistry, 1996. 271(11): p. 6071-6.

91. Alimandi, M., et al., Epidermal growth factor and betacellulin mediate signal transduction through co-expressed ErbB2 and ErbB3 receptors. Embo j, 1997. 16(18): p. 5608-17.

92. Holbro, T., et al., The ErbB2/ErbB3 heterodimer functions as an oncogenic unit: ErbB2 requires ErbB3 to drive breast tumor cell proliferation. Proc Natl Acad Sci U S A, 2003. 100(15): p. 8933-8.

93. Wilson, T.R., et al., Neuregulin-1-mediated autocrine signaling underlies sensitivity to HER2 kinase inhibitors in a subset of human cancers. Cancer Cell, 2011. 20(2): p. 158-72.

94. Qiu, Y., L. Ravi, and H.J. Kung, Requirement of ErbB2 for signalling by interleukin-6 in prostate carcinoma cells. Nature, 1998. 393(6680): p. 83-5.

95. Pathak, B.G., et al., Mouse chromosomal location of three EGF receptor ligands: amphiregulin (Areg), betacellulin (Btc), and heparin-binding EGF (Hegfl). Genomics, 1995. 28(1): p. 116-8. 
96. Wang, Y.N. and M.C. Hung, Nuclear functions and subcellular trafficking mechanisms of the epidermal growth factor receptor family. Cell Biosci, 2012. 2(1): p. 13.

97. Wiley, H.S., Trafficking of the ErbB Receptors and its Influence on Signaling. Exp Cell Res, 2003. 284(1): p. 78-88.

98. Threadgill, D.W., et al., Targeted disruption of mouse EGF receptor: effect of genetic background on mutant phenotype. Science, 1995. 269(5221): p. 230-4.

99. Mann, G.B., et al., Mice with a null mutation of the TGF alpha gene have abnormal skin architecture, wavy hair, and curly whiskers and often develop corneal inflammation. Cell, 1993. 73(2): p. 249-61.

100. Dahlhoff, M., et al., Genetic deletion of the EGFR ligand epigen does not affect mouse embryonic development and tissue homeostasis. Exp Cell Res, 2013. 319(4): p. 529-35.

101. Ceresa, B.P., et al., Epidermal Growth Factor Receptor, in Encyclopedia of Signaling Molecules. 2016, Springer New York : New York, NY. p. 1-11.

102. Sasada, R., et al., Cloning and expression of cDNA encoding human betacellulin, a new member of the EGF family. Biochemical and biophysical research communications, 1993. 190(3): p. 1173-9.

103. Schneider, M.R., et al., Beyond wavy hairs: the epidermal growth factor receptor and its ligands in skin biology and pathology. The American Journal of Pathology, 2008. 173(1): p. 14-24.

104. Schneider, M.R., et al., Betacellulin regulates hair follicle development and hair cycle induction and enhances angiogenesis in wounded skin. J Invest Dermatol, 2008. 128(5): p. 1256-65.

105. Moon, W.S., et al., Expression of betacellulin and epidermal growth factor receptor in hepatocellular carcinoma: implications for angiogenesis. Hum Pathol, 2006. 37(10): p. 1324-32.

106. Singh, B., G. Carpenter, and R.J. Coffey, EGF receptor ligands: recent advances. F1000Res, 2016. 5.

107. Singh, B. and R.J. Coffey, Trafficking of Epidermal Growth Factor Receptor Ligands in Polarized Epithelial Cells. Annual review of physiology, 2013.

108. Lopez-Torrejon, I., et al., Human betacellulin structure modeled from other members of EGF family. J Mol Model, 2002. 8(4): p. 131-44.

109. Dahlhoff, M., et al., Betacellulin overexpression in transgenic mice improves glucose tolerance and enhances insulin secretion by isolated islets in vitro. Mol Cell Endocrinol, 2009. 299(2): p. 188-93.

110. Watanabe, T., et al., Recombinant human betacellulin. Molecular structure, biological activities, and receptor interaction. The Journal of biological chemistry, 1994. 269(13): p. 9966-73.

111. Schoeberl, B., et al., Therapeutically targeting ErbB3: a key node in ligand-induced activation of the ErbB receptor-PI3K axis. Sci Signal, 2009. 2(77): p. ra31.

112. Rush, J.S., J.L. Peterson, and B.P. Ceresa, Betacellulin (BTC) Biases the EGFR to Dimerize with ErbB3. Mol Pharmacol, 2018.

113. Robertson, D.M., et al., Characterization of Growth and Differentiation in a TelomeraseImmortalized Human Corneal Epithelial Cell Line. Inv Opth Vis Sci, 2005. 46(2): p. 470478.

114. Schneider, C.A., W.S. Rasband, and K.W. Eliceiri, NIH Image to ImageJ: 25 years of image analysis. Nature methods, 2012. 9(7): p. 671-5. 
115. Vedham, V., H. Phee, and K.M. Coggeshall, Vav Activation and Function as a Rac Guanine Nucleotide Exchange Factor in Macrophage Colony-Stimulating Factor-Induced Macrophage Chemotaxis. Mol Cell Biol, 2005. 25(10): p. 4211-4220.

116. Rush, J.S. and B.P. Ceresa, RAB7 and TSG101 are required for the constitutive recycling of unliganded EGFRs via distinct mechanisms. Mol Cell Endocrinol, 2013. 381(1-2): p. 18897.

117. Stepp, M.A., et al., Wounding the cornea to learn how it heals. Exp Eye Res, 2014. 121: p. 178-93.

118. Riese, D.J., 2nd, et al., Betacellulin activates the epidermal growth factor receptor and erbB-4, and induces cellular response patterns distinct from those stimulated by epidermal growth factor or neuregulin-beta. Oncogene, 1996. 12(2): p. 345-53.

119. Yamashiro, D.J. and F.R. Maxfield, Acidification of morphologically distinct endosomes in mutant and wild-type Chinese hamster ovary cells. J Cell Biol, 1987. 105(6 Pt 1): p. 272333.

120. Macdonald-Obermann, J.L. and L.J. Pike, Different epidermal growth factor (EGF) receptor ligands show distinct kinetics and biased or partial agonism for homodimer and heterodimer formation. J Biol Chem, 2014. 289(38): p. 26178-88.

121. Lyons, D.A., et al., erbb3 and erbb2 are essential for schwann cell migration and myelination in zebrafish. Curr Biol, 2005. 15(6): p. 513-24.

122. Sathyamurthy, A., et al., ERBB3-mediated regulation of Bergmann glia proliferation in cerebellar lamination. Development, 2015. 142(3): p. 522-32.

123. Reschke, M., et al., HER3 Is a Determinant for Poor Prognosis in Melanoma. Clinical Cancer Research, 2008. 14(16): p. 5188-5197.

124. Khan, I.H., et al., Microbead arrays for the analysis of ErbB receptor tyrosine kinase activation and dimerization in breast cancer cells. Assay Drug Dev Technol, 2010. 8(1): p. 27-36.

125. Knudsen, S.L., et al., EGFR signaling patterns are regulated by its different ligands. Growth Factors, 2014. 32(5): p. 155-63.

126. Kinzer-Ursem, T.L. and J.J. Linderman, Both ligand-and cell-specific parameters control ligand agonism in a kinetic model of $g$ protein-coupled receptor signaling. PLoS Comput Biol, 2007. 3(1): p. e6.

127. Zidar, D.A., et al., Selective engagement of $G$ protein coupled receptor kinases (GRKs) encodes distinct functions of biased ligands. Proceedings of the National Academy of Sciences, 2009. 106(24): p. 9649-9654.

128. Luttrell, L.M. and T.P. Kenakin, Refining Efficacy: Allosterism and Bias in G ProteinCoupled Receptor Signaling, in Signal Transduction Protocols, L.M. Luttrell and S.S.G. Ferguson, Editors. 2011, Humana Press: Totowa, NJ. p. 3-35.

129. Pinkas-Kramarski, R., et al., Diversification of Neu differentiation factor and epidermal growth factor signaling by combinatorial receptor interactions. Embo j, 1996. 15(10): p. 2452-67.

130. Riese, D.J., 2nd, et al., The cellular response to neuregulins is governed by complex interactions of the erbB receptor family. Mol Cell Biol, 1995. 15(10): p. 5770-6.

131. Steinkamp, M.P., et al., erbB3 is an active tyrosine kinase capable of homo- and heterointeractions. Mol Cell Biol, 2014. 34(6): p. 965-77.

132. Chiba, T., What are the real roles of different erbB proteins in Barrett's Esophagus. Digestion, 2004. 70(2): p. 93-4. 
133. Macdonald-Obermann, J.L., et al., Dynamic analysis of the epidermal growth factor (EGF) receptor-ErbB2-ErbB3 protein network by luciferase fragment complementation imaging. The Journal of biological chemistry, 2013. 288(42): p. 30773-84.

134. Rossi, A., et al., Genetic compensation induced by deleterious mutations but not gene knockdowns. Nature, 2015. 524: p. 230.

135. Krumins, A.M. and A.G. Gilman, Targeted knockdown of $G$ protein subunits selectively prevents receptor-mediated modulation of effectors and reveals complex changes in non-targeted signaling proteins. J Biol Chem, 2006. 281(15): p. 10250-62.

136. Garrett, J.T., et al., Transcriptional and posttranslational up-regulation of HER3 (ErbB3) compensates for inhibition of the HER2 tyrosine kinase. Proc Natl Acad Sci U S A, 2011. 108(12): p. 5021-6.

137. Seno, M., et al., Human betacellulin, a member of the EGF family dominantly expressed in pancreas and small intestine, is fully active in a monomeric form. Growth Factors, 1996. 13(3-4): p. 181-91.

138. Olayioye, M.A., et al., The ErbB signaling network: receptor heterodimerization in development and cancer. Embo j, 2000. 19(13): p. 3159-67.

139. Yarden, Y. and M.X. Sliwkowski, Untangling the ErbB signalling network. Nat Rev Mol Cell Biol, 2001. 2(2): p. 127-37.

140. Macro, L., J.K. Jaiswal, and S.M. Simon, Dynamics of clathrin-mediated endocytosis and its requirement for organelle biogenesis in $\langle e m>$ Dictyostelium</em>. Journal of Cell Science, 2012. 125(23): p. 5721-5732.

141. Sorkin, A. and A. Fortian, Endocytosis and Endosomal Sorting of Receptor Tyrosine Kinases, in Receptor Tyrosine Kinases: Structure, Functions and Role in Human Disease, L.D. Wheeler and Y. Yarden, Editors. 2015, Springer New York: New York, NY. p. 133-161.

142. Kornilova, E., et al., Lysosomal targeting of epidermal growth factor receptors via a kinase-dependent pathway is mediated by the receptor carboxyl-terminal residues 1022 1123. J Biol Chem, 1996. 271(48): p. 30340-6.

143. Stern, K.A., T.L. Place, and N.L. Lill, EGF and amphiregulin differentially regulate Cbl recruitment to endosomes and EGF receptor fate. Biochem J, 2008. 410(3): p. 585-94.

144. Humtsoe, J.O. and R.H. Kramer, Differential epidermal growth factor receptor signaling regulates anchorage-independent growth by modulation of the PI3K/AKT pathway. Oncogene, 2010. 29(8): p. 1214-26.

145. Yamada, H., et al., Potentiation of mitogenic activity of platelet-derived growth factor by physiological concentrations of insulin via the MAP kinase cascade in rat A10 vascular smooth muscle cells. Int J Exp Diabetes Res, 2002. 3(2): p. 131-44.

146. Sadremomtaz, A., et al., Dual blockade of VEGFR1 and VEGFR2 by a novel peptide abrogates VEGF-driven angiogenesis, tumor growth, and metastasis through PI3K/AKT and MAPK/ERK1/2 pathway. Biochim Biophys Acta Gen Subj, 2018. 1862(12): p. 26882700.

147. Hynes, N.E. and G. MacDonald, ErbB receptors and signaling pathways in cancer. Curr Opin Cell Biol, 2009. 21(2): p. 177-84. 


\section{APPENDICES}

Appendix 1

\section{Council}

Edward T. Morgan

Prosidert

Emary Univenity Sctool of

Medcin

Wayno L Backec

Prosidari-Eled

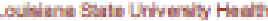

Sclarcen Cerme:

John D. Sohuetz

Pail Arasident

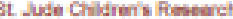

Hospent

Margaret E Gnegy

Macrosinitroul

Uhiverity of Midigan Moded

Sctioel

Jin Zhang

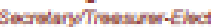

Unversity of Calloria, Ean Diego

John J. Tocmer

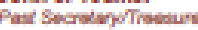

Purdie Universy

Carol L. Beok

Councilor

Thoma Jeflerson Univershy

Alan V. Imroka

Councilor

Giversity of Michigan Moded

Sctiod

Kathryn A. Cunningham

Counaky

University of Texas Maded

Granch

Mary E Vore

Cher Bowed of Aloblowions

Thereas

Universily of Kentucley

Brian M. Cox

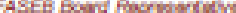

Bethesda MD

Mlohael W. Wood

Cher, Arogrum Conevitos

Nospham LIC

Judlth A. sluolak

frective celiar
October 3, 2018

Jamle Sue Rush

505 South Hancock St.

Ctr RM 352E

Loulsville, KY 40202

Emall: jamle.rushgioulsville.edu

Dear Jamle S. Rush:

This is to grant you permission to Include the following article in your dissertation entitled "Epldemal Growth Factor-LIke LIgands Regulate Dimer Selection" for the University of Loulsville:

JS Rush, JL Peterson, and BP Ceresa (2018) Betacellulln (BTC)

Blases the EGFR to Dimerize with ErbB3, Mol Pharmacol, DOl:

httos/idol.org/10.1124/mol.118.113399

On the first page of each copy of this article, please add the folowing:

Reprinted with permission of the American Soclety for Pharmacology and Experimental Therapeutics. All rights reserved.

In addition, the original copyright line published with the paper must be shown on the coples Included with your dissertation.

Sincerely yours,

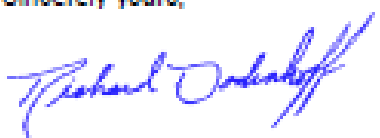

Richard Dodenhorf Joumals Director

Transforming Discoveries into Therapies

ASPET - 1801 Rockville Pike, Suite 210 - Rockville, MD 20852 - Office: 301-634-7060 - aspet.org f y in 


\title{
CURRICULUM VITAE
}

\author{
Jamie S. Rush
}

831 Markham Ln · Louisville, KY $40207 \cdot(405) 306-6980 \cdot$ missjamierush@gmail.com

\section{EDUCATION}

- University of Louisville-Louisville

Masters of Science in Pharmacology and Toxicology, December 2018

- University of Oklahoma-Norman

Bachelors of Science in Microbiology, May 2001

- Tulsa Community College -Tulsa

Associates of Science in Chemistry, August 1998

\section{EXPERIENCE}

RESEARCH TECHNOLOGIST II, UNIVERSITY OF LOUISVILLE HSC $\quad$ July 2012-Present

- Molecular biology and recombinant DNA techniques such as, plasmid isolation and characterization, bacterial transformation, site-directed mutagenesis, and sequence analysis.

- Cell imaging including immunofluorescence, brightfield, widefield, and confocal microscopy.

- Protein purification and isolation techniques such as SDS-PAGE Western blotting and density gradient.

- Mammalian cell culture techniques using eukaryotic transient and stable cell transfection, Boyden Chamber migration, scratch assay and silicone plug assay.

- Experienced in animal handling and corneal epithelial surgery

- Responsible for laboratory supply management including inventory control, ordering and account reconciliation.

- Accountable for equipment maintenance and repairs.

- Create figures for publication with Photoshop from collected data and analyze with various software including image J, Graphpad/Prism and Excel.

- Manage lab assistants and provide support for all laboratory staff and students

RESEARCH ASSISTANT I, UNIVERSITY OF OKLAHOMA HSC February 2010 - June 2012

- Molecular biology and recombinant DNA techniques such as, plasmid isolation and characterization, bacterial transformation, and sequence analysis.

- Cell imaging including immunofluorescence. 
- Protein purification and isolation techniques such as SDS-PAGE Western blotting and density gradient.

- Mammalian cell culture techniques using eukaryotic transient and stable cell transfection, Boyden Chamber migration, scratch assay and silicone plug assay.

- Responsible for laboratory supply management including inventory control, and ordering.

- Accountable for equipment maintenance and repairs.

- Create figures for publication with Photoshop from collected data and analyze with various software including image J, Graphpad/Prism and Excel.

- Manage technicians and provide support for all laboratory staff and students.

LABORATORY MANAGER, TEC-AN, INC.

January 2004-February 2010

- Revised policy and procedure manual to insure compliance with National Voluntary Laboratory Accreditation Program and the American Industrial Hygiene Association.

- Created, managed and organized new laboratory facility.

- Accountable for daily time management and analysis of laboratory samples.

- Responsible for laboratory and microscope maintenance and calibration.

- Generated excel spreadsheets for statistical analysis of laboratory and individual error rates.

- Developed and presented monthly, semi-annual and annual quality control reports to $Q A / Q C$ officer.

- Produced customer reports for sample analysis with continued customer service for complaints, concerns or requests from clients.

- Negotiated pricing for government and non-government customers.

- Responsible for marketing of laboratory services including creating TEC-AN's first website.

LABORATORY TECHNICIAN,TEC-AN, Inc.

June 2001- January 2004

- Organized daily sample analysis.

- Responsible for marketing of new customers.

- Maintained proficiency with National Voluntary Laboratory Accreditation Program and the American Industrial Hygiene Association.

- Oversea cleanliness and calibration of laboratory equipment and facilities.

- Received and accepted customer samples and ensured chain-of-custody procures were followed.

- Maintained integrity and privacy of customer confidential reports and records.

UNIVERSITY OF OKLAHOMA, NORMAN OKLAHOMA

August 2000 - May 2001

Microbiology Department, Independent study with Dr. Ralph S. Tanner

- Created anaerobic media for growth patterns and recovery rates of coliforms.

- Researched and documented laboratory results.

- Presented results weekly to Dr. Tanner.

\section{PUBLICATIONS}


- Rush JS, Peterson JL, Ceresa BP, "Betacellulin (BTC) Biases the EGFR to Dimerize with ErbB3", Molecular Pharmacology 2018 Nov 1 [Epub ahead of print Sept 24]

- Brian P. Ceresa, Julie A. Gosney, Nicole M. Jackson, Jamie S. Rush, "Epidermal Growth Factor Receptor", Encyclopedia of Signaling Molecules, Second Edition

- Rush JS, Bingaman DP, Chaney PG, Wax MB, Ceresa BP, "Administration of Menadione, Vitamin K3, Ameliorates Off-Target Effects of Corneal Epithelial Wound Healing Due to Receptor Tyrosine Kinase Inhibition", Investigative Ophthalmology \& Visual Science 2016 Nov 1;57(14):5864-5871

- Hudson SV, Huang JS, Yin W, Albeituni S, Rush J, Khanal A, Yan J, Ceresa BP, Frieboes HB, McNally LR, "Targeted Noninvasive Imaging of EGFR-Expressing Orthotopic Pancreatic Cancer Using Multispectral Optoacoustic Tomography", Journal of Cancer Research 2017 Nov 1:74:6271-6279

- $\quad$ Rush JS, Boeving MA, Berry WL, Ceresa BP, "Antagonizing c-Cbl enhances EGFRdependent corneal epithelial homeostasis", Investigative Ophthalmology \& Visual Science 2014 Jul 1:55(8):4691-9, PMID: 24985478

- Rush JS, Ceresa BP, "RAB7 and TSG101 are required for the constitutive recycling of unliganded EGFRs via distinct mechanisms", Molecular and Cellular Endocrinology 2013 Dec5:381(1-2):188-197.

- Rush JS, Quinalty LM, Engelman L, Sherry DM, Ceresa BP, "Endosomal accumulation of the activated epidermal growth factor receptor (EGFR) induces apoptosis.", J Biol Chem. 2012 Jan2:287(1):712-22. Epub 2011 Nov 18.

\section{PRESENTATIONS}

- Rush JS, Ceresa BP, Peterson JL; EGFR Ligands EGF and BTC Illicit Different Cellular Response in Corneal Cells, Abstract and poster presentation at annual RESEARCH! Louisville, Louisville, KY, 2017; GRM-18

- Rush JS, Ceresa BP, Peterson JL; BTC and EGF Elicit Different Cellular Response Through EGFR, Abstract and poster presentation at annual RESEARCH! Louisville, Louisville, KY, 2016; GRM-21

- Rush JS, Ceresa BP, Griffey HL; ErbB3 as a Regulator of EGFR Signaling. Abstract and poster presentation at annual ASCB meeing, San Diego, CA, 2015; B1245

- Rush JS, Ceresa BP, Griffey HL; ErbB3 as a Regulator of EGFR Signaling. Abstract and poster presentation at annual RESEARCH! Louisville, Louisville, KY, 2015; GRM-14

- Rush, JS, Boeving, MA, Berry, WL, Ceresa, BP; C-Cbl As A Therapeutic Target For Enhanced Human Corneal Epithelial Wound Healing. Abstract and poster presentation at ASCB Annual Meeting, New Orleans, Louisiana, 2013; b673/1354

- Rush, JS, Boeving, MA, Berry, WL, Ceresa, BP; C-Cbl As A Therapeutic Target For Enhanced Human Corneal Epithelial Wound Healing. Abstract and poster presentation at Annual Brown Cancer Center Retreat

- Rush, JS, Boeving, MA, Berry, WL, Ceresa, BP; C-Cbl As A Therapeutic Target For Enhanced Human Corneal Epithelial Wound Healing. Abstract and poster presentation at Annual RESEARCH! Louisville, Louisville, KY, 2013; RS-69

\section{CERTIFICATIONS}

- Moore Norman Technology Center, Norman Oklahoma NIOSH 582e 